\title{
ANALYSIS OF THE TRANSIENT STABILITY LIMIT OF NIGERIA'S 330kV TRANSMISSION SUB-NETWORK
}

\author{
P. 0. Oluseyi ${ }^{1}$, T. S. Adelaja ${ }^{2}$ and T. 0. Akinbulire ${ }^{3}$ \\ 1,2,3DEPARTMENT OF ELECTRICAL/ELECTRONICS ENGINEERING, UNIVERSITY OF LAGOS, LAGOS STATE, NIGERIA \\ E-mail addresses: ${ }^{1}$ poluseyi@unilag.edu.ng, ${ }^{2}$ tyadelaja@gmail.com, ${ }^{3}$ takinbulire@unilag.edu.ng
}

\begin{abstract}
The poor investment in the network expansion programme has led to high level of grid fragility experienced in the power transmission system in Nigeria. Thus, any little disturbance often results in cascaded outage which is very hazardous to the power system equipment and operation. In order to overcome or ameliorate the influence of this challenge, the network engineers have to devise methodologies based on the dynamic stability analysis. This motivates the development of power system transient stability model presented herein. The developed model is thus applied to a specimen of the Nigeria's transmission power system, i.e. the Ikeja-West Sub-network. This choice is influenced by the fact that the Ikeja-West sub-network is the hub of power transmission arteries in Nigeria. Thus the Electrical Transient and Analysis Program (ETAP) software is deployed to operate on the ensuing model. This then leads to generating a series of results that demonstrates the different scenarios in respect of the system stability studies. The method adopted is quite appealing and promising as a tool in sustaining system stability and security during slight disturbance to the network during operation.
\end{abstract}

Keywords: Disturbance, Transient stability, Grid Fragility, Network, Nigerian Sub-Transmission System, Transient Model, Transmission system,

\section{INTRODUCTION}

In recent time, the management of power systems has proven to be more difficult than in the past. This is due to recent increased competition (existing power systems are required to provide same service at lower cost), environmental constraints and other factors have conspired; thus limiting the expansion of the transmission network [1].

The deregulation and unbundling of the power sector has witnessed a sudden increase in the demand for electricity with economic consideration as a top priority. The modern deregulated electricity environment has driven utilities, around the world, so as to operate the power systems closer to the stability thresholds to ensure more efficient utilization of transmission networks [2]. This development has opened a new opportunity for power system operators, whereby at the same time, put the system under considerable pressure to strike a balance between more profit on one hand and fear of possible loss of the system on the other hand.

Critical analysis of recent widespread occurrence of power outages (worldwide) showed that blackouts is recorded whenever the sequence of normal contingencies exceeds the acceptable security limits and reliability margins [3]. It can also be noted that large power system failure is a rare event that are difficult to predict; so also, much tedious to control.

In order to maintain stability of power system, there are two very important parameters which are namely: the fault clearing time (FCT) and critical clearing time (CCT). The FCT is defined as the time at which fault is cleared after the occurrence of the fault; always recorded in (seconds). Whereas, the CCT is the fault clearing time at which the system is critically stable, also measured in seconds [4].

In the case of Nigeria, the power network is constructed to generate and wheel power to load centers at specific voltage and frequency levels with statutory limits. The nominal frequency is $50 \mathrm{~Hz} \pm 0.5 \%$. Even though there are possibilities for system stress; the power system variation, statutorily, could be $50 \mathrm{~Hz} \pm 2.5 \%$. (i.e. 48.75 $\mathrm{Hz}-51.25 \mathrm{~Hz})$. On the other hand, the nominal transmission system voltage levels are $330 \mathrm{kV}$ and $132 \mathrm{kV}$; in the case of the latter, it has a statutory limit stated as $132 \mathrm{kV} \pm 0.5 \%$. However, when the power system is under stress or during system faults, voltages can deviate outside the limits by a further $5 \%$ except under transient and sub-transient disturbances. 
Due to the inadequacy of the transmission network capacity, the power system could be stressed to such as an extent that relatively small disturbance can cause a great upset which may eventually result in a possible voltage collapse. In addition, the present architecture of power systems worldwide supports the idea that larger area of the systems be interconnected so as to maximize power generation/transmission efficiency as well as effective power transfer. This implies that a significant portion of the system will be affected whenever/wherever there is any noticeable system disturbance.

In this paper, the IKEJA WEST $330 \mathrm{kV}$ transmission subnetwork was investigated for transient stability. In which case, evaluating its response to sudden/large disturbance (fault conditions) on adjoining transmission lines connected to the station. The systems transition from a perturbed state to a normal operating state with respect to varying critical clearing time (CCT) was documented. Special attention was paid to the EGBINIKEJA WEST line (since EGBIN delivers the highest quantum of power to the station).

The system under examination was modeled and simulated on the ETAP software. The ETAP is a real-time system simulator with special features that include the ability to perform studies both at on-load and off-load conditions. More importantly, it could be implemented for interconnected systems as well as isolated systems. The voltage and frequency deviation was thus plotted against the time. At the end of this study, security limit for faults occurring on the IKEJA-WEST bus was determined, thereby supplying relevant information on the weak points in the system. This made it easy to suggest ideas towards reinforcing network security.

\section{TRANSIENT STABILITY ANALYSIS}

Transient faults are a usual occurrence in interconnected systems. They usually clear if power is removed from the line and then restored after a short while.

Transient stability is the ability of a power system to regain its normal operating condition after sudden and severe disturbance in the system [5]. Power stability assessment plays an important role in determining the system operating limits and operating guidelines [6]. These analyses also aim to establish the power supply system's reliability and its ability to withstand various disturbances [7].

Several occurring contingencies are however beyond the anticipated transient limits of the system. These contingencies can result in overloading and cascaded trip of protection schemes on the line.

Several voltage collapse scenarios have been witnessed around the world in recent times. For instance, in the
United States; a country with proven infrastructure and high reliability, the majority of the current U.S. power grid infrastructure was built in the 1930s [8]. The aging and overburdened power grid has experienced five massive blackouts in the past 40 years [8]. In fact, more than 50 cases of voltage instability or collapse were reported all over the world between 1965 and 1996 [9] and in Nigeria, nine (9) full and five (5) partial system collapse occurred between January and June 2012 [10]. So also the Nigerian power grid has experienced sixteen (16) complete and five (5) partial collapses in the first six (6) months in 2016 alone [11]. References [12,13 and 14] carried out research on power outages in Nigerian transmission grid, the results of which are highly informative on the debilitating influence of fault occurrence. According to [13], research progress and anticipated research challenges related to the future power grid, using the United States as a case study was carried out. This culminated in the conclusion that protection engineers could only rely on adequate protection to prevent the system from widespread effect of fast disturbances. Reference [14] presented an indepth study of the ravaging effect of the voltage collapse on the Nigerian National Grid. In which case, the authors itemized several causes of voltage collapse in the Nigerian power system but this work lacks any form of simulated results to buttress several solutions proffered therein. In the case of Reference [12]; the simulation displayed the power outages in the Nigerian Power System did not use ETAP software but rather employed the Power World Simulator Software for the analysis. The authors in [15]-[16] assessed the dynamic security of the $330 \mathrm{kV}$ Nigeria power network. The investigation also carried out series of simulation of the ensuing faults on the buses only; while there was no consideration for the system transient stability resulting from the influence of the fault on the transmission lines. The study in [17] considered the impacts of distributed generation on power system transient as well as the voltage stability assessment.

In references [18-24]; series of investigation was carried out on the voltage stability enhancement methods using the flexible alternating current transmission systems (FACTS) devices. Several numerical techniques have been used to solve transient stability problems. Such techniques include Dynamic stability analysis and performance of the system as depicted in [25]. The Single Machine Equivalent (SME) technique for the analysis of the system's transient stability studies was used in [26]. While in [27], the extreme learning method was implemented to predict the power system's critical clearing time. A new twist was introduced when the concept of Lyapunov exponents was used deployed to 
analyze transient stability in [28]. In all these analyses, the time of clearance as well as the degree of criticality was not well entrenched.

Thus this research work evaluated transient stability analysis for the IKEJA WEST Sub-Network considering the effect of transmission line faults with regard to the generators working in synchronism. Plots and graphs as a result of this study are presented in the results and discussion section.

\section{MATERIALS AND METHODS}

\subsection{Mathematical Techniques}

Under normal conditions, the electrical system is assumed to be operating at its stable pre-fault equilibrium point. The behavior of such system is given by:

$$
M \frac{d^{2} \partial}{d t^{2}}=P m-P e
$$

In (1), $M$ is the Inertia Constant, $P_{m}$ is the Input Mechanical Power, and $\mathrm{P}_{\mathrm{e}}$ is the Output Electrical Power Thus for small excursions of the rotor angle $(\Delta \partial)$, equation (1) becomes:

$$
M \frac{d^{2} \Delta \partial}{d t^{2}}=\Delta P m-\Delta P e
$$

Whereby the mechanical power of the generator is assumed to be constant then $\Delta P m=0$. Therefore equation (2) becomes:

$$
M \frac{d^{2} \Delta \partial}{d t^{2}}=-\Delta P e
$$

which can be rewritten as:

and

$$
\begin{gathered}
M \frac{d^{2} \Delta \partial}{d t^{2}}=\Delta P m-\Delta P e \\
\frac{d^{2} \Delta \partial}{d t^{2}}=-\frac{1}{M} \partial P e \quad \Delta \partial=-\frac{K s}{M} \Delta \partial
\end{gathered}
$$

Where $K_{s}=$ Synchronizing power coefficient Thus,

$$
\frac{d^{2} \Delta \partial}{d t^{2}}+\frac{K s}{M} \Delta \partial=0
$$

Further solution to the differential equation above provides two roots.

$$
\lambda_{1} \lambda_{2}= \pm \sqrt{\frac{K s}{M}}
$$

If the synchronizing torque $\mathrm{K}_{\mathrm{s}}$ is positive, then the system will oscillate with imaginary roots $\lambda_{1} \lambda_{2}= \pm j \omega_{s}$; where $\omega_{s}$ is the synchronous angular acceleration and attain stability at a different rotor angle. On the other hand, if the synchronizing torque $K s$ is negative. The roots are real which characterizes system instability.

The swing equation as applied in this research work shows that the solution of the generator's rotor angle is a function of balance between mechanical power and electrical power. Any disturbance in the system, altering this balance will cause the rotor angle to undergo a transient and reach a new position in an oscillatory manner.

\subsection{System modelling}

The IKEJA WEST $330 / 132 \mathrm{kV}$ transmission station is considered strategic and unique to the Nigerian National Grid. The station has seven (7) incoming $330 \mathrm{kV}$ lines, two (2) $330 \mathrm{kV}$ outgoing lines and fourteen (14) $132 \mathrm{kV}$ outgoing lines to step down transmission stations in the network. The $330 \mathrm{kV}$ lines connected to the IKEJA WEST Station are named according to nomenclature as

i. Oshogbo $330 \mathrm{KV}$ line (Cct H1W)

ii. Olorunsogo $330 \mathrm{KV}$ line (R1W) formerly known as Ayede $330 \mathrm{KV}$ line (Cct W2A)

iii. Omotosho $330 \mathrm{KV}$ line (M5W) formerly known as Benin 330KV line 1 (Cct B5W)

iv. EGBIN 330KV line 3 (N6W) formerly known as Benin 330KV line 2 (Cct B6W)

v. Oke-Aro $330 \mathrm{KV}$ line 1 (Cct N7W)

vi. Oke-Aro $330 \mathrm{KV}$ line 2 (Cct N8W)

vii. Sakete $330 \mathrm{KV}$ line (NW1BS)

viii. Akangba $330 \mathrm{kV}$ line

ix Sakete $330 \mathrm{kV}$ line

The transmission station is fed from both hydro power stations (supply from Osogbo) and thermal power generating stations i.e. Omotosho power station, EGBIN power station and AES power station. The transmission station consists of four (4) 150MVA step-down transformer (resulting in a total station capacity of $600 \mathrm{MVA}$ or $480 \mathrm{MW}$ ) for stepping the incoming $330 \mathrm{kV}$ to $132 \mathrm{kV}$. Transformer nomenclatures given as: T1A, T1B, T2A and T2B. Two (2) 75MX reactors R1 and R2 are connected to the $330 \mathrm{kV}$ bus-bar for voltage stability. Two earthing transformers (GT1A and GT2A) are attached to the transformers. GT1A is connected to the tertiary of T1A while GT2A is connected to the tertiary of T2A. The power transformers are connected to a breaker which operates to clear fault on the line and prevent further degradation/damage. The breakers are to safeguard the line by making or breaking contact when the need to isolate arises.

\section{METHOD OF ANALYSIS}

The single line diagram (SLD) of the test system (IKEJA WEST transmission station) simulated on ETAP is shown in Figure 1. The load and generator parameters for the purpose of this test is given in the appendix section, the generators are assumed to be operating at $80 \%$ of their maximum installed capacity with the highest been the EGBIN thermal station. The system voltage level is $330 \mathrm{kV}$. Due to the capacity of the EGBIN thermal power plant, it will be assumed as the power swing bus for the 
system (ETAP requires at least one swing bus during modeling) while the Olorunsogo power plant and Omotosho will be on voltage control.

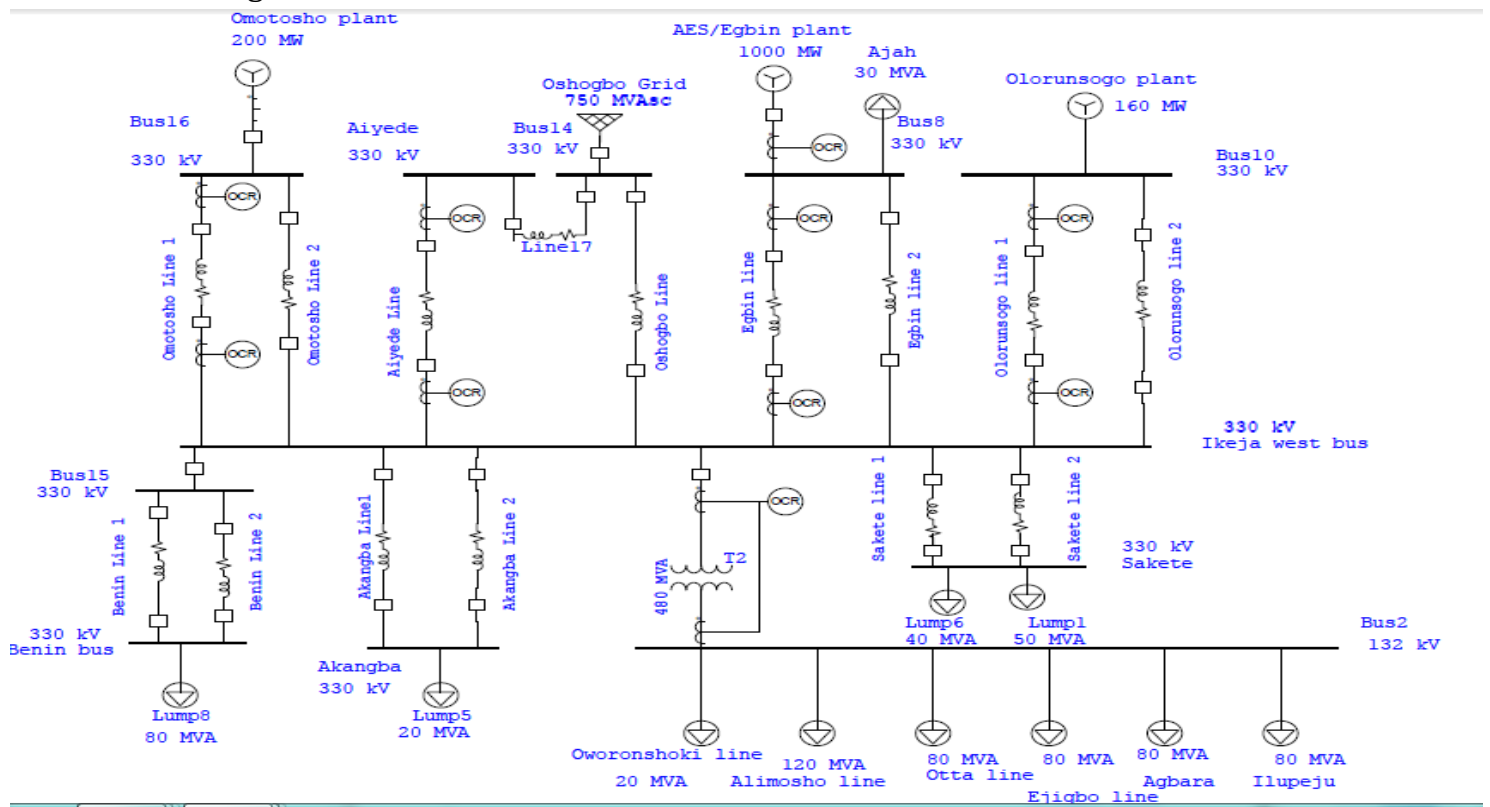

Fig.1. Single Line Diagram of the IKEJA-WEST sub-network

The Transient Stability Analysis module on the ETAP software (windows 7 operating environment) is used to investigate the test system dynamic responses and stability limits before, during, and after system disturbances. User defined events and actions will be implemented to find out the system and machine responses in time domain. The transmission substation will be simulated and represented as accurately as possible. The information for the accurate representation of this test system was obtained through an authorized data gathering from the TCN (Transmission Company of Nigeria) substation. Typical values of machine parameters such as steady state and dynamic data that could not be obtained from TCN (Transmission Company of Nigeria) was implemented for simulation in this research work. The system's network equation and machine differential equation will be solved interactively to find out the system and machine responses in time domain. A three phase (most severe of the fault types) is created on the EGBIN transmission line and IKEJA WEST substation bus. Different scenarios for fault creation and clearance will be specified (this is known as "events" in ETAP). The different generator plots for fault creation and clearance at different scenarios (which represents the case studies or events) will be displayed and analyzed.

The system is assumed to be under load conditions currently supplied by the power stations as at the time of this study. The load is represented in ETAP as lumped load (30\% static load and 70\% synchronous load). All shunt connected branches and static loads do not contribute fault current in power station during fault condition. The required data for the system representation in ETAP which would be gathered during the field study of the network include;

- One-line diagrams (showing relay and protection devices)

- Power Grid Fault Current Data and Protective Device Settings

- Transformer Data

- Load Data

- System Operating Current

- Cable / Conductor Data

- Bus / Switchgear Data

- Instrument Transformer Data (CT, VT)

- Transmission line tower data

- Other Protective Device (PD) Data

The elements in the power system that contribute current during a short circuit fault are generators/power grid, synchronous motors, induction machines, lump loads, inverters while elements like static loads, motor operated valves and all shunt connected branches do not contribute current in the power station during short circuit faults. The system was adequately represented in ETAP software environment by modelling each unit of the system highlighted above and interconnecting to form the single line diagram.

\section{RESULTS AND DISCUSSION}

The performance of the IKEJA-WEST 330kV transmission sub-network is depicted in this section. The generation profiles of the power stations connected to the IKEJA 
WEST bus bar is shown in Fig. 2. This analysis assumes that $80 \%$ of the installed capacities of these substations are available for utilization as shown in Table 1.

Table 1: Capacity of Power Stations Connected Directly To Ikeja-West

\begin{tabular}{llll}
\hline S/N & Station & $\begin{array}{l}\text { Installed } \\
\text { Capacity (MW) }\end{array}$ & $\begin{array}{l}\text { Available } \\
\text { Capacity (MW) }\end{array}$ \\
\hline 1 & Eame & 1504 & 1000 \\
2 & Ombin/AES & 250 & 200 \\
3 & Olorunsogo & 200 & 160 \\
\hline
\end{tabular}

The Egbin power station is used as reference since it supplies the highest power to the IKEJA-WEST bus. In order to increase the accuracy of the calculations in ETAP, a simulation time step of 0.001 was used. A series of fault occurrence is herein considered underneath as scenario 1 and scenario 2.

Scenario 1

A three phase fault was created at 50\% (mid-point) of the EGBIN-IKEJA WEST transmission line. The fault was created at time $10.5 \mathrm{~s}$ and cleared at $10.7 \mathrm{~s}$. The simulation lasted for 200s. The generators remain in synchronism as shown in the Figures 3 and 4.

After the fault has been cleared, Omotosho, AES/Egbin and Olorunsogo generators are now operating at a new rotor angle of -12.3 degs, 21.3 degs and -8.5 degs respectively as can be seen in Fig. 2 .

It is easily observed from Fig. 3, 4 and 5 that the generators have been disturbed due to the fault. The generators have undergone power angle swing. And after the fault had been removed, it oscillated and was damped gradually but they will attain stability after a period of time as the disturbance curve decayed away with time (t). The generators will now operate at a new rotor angle as can be depicted in Fig 2. The blue, green and red plots in fig. 3 represent the relative power angles of AES/Egbin, Olorunsogo and Omotosho power generators respectively. It is easily seen in the figure 2 that $97.02 \%$ of the grid voltage was restored after the transient fault. Frequency was also at $49.94 \mathrm{~Hz}$ (within acceptable limit of $50 \mathrm{~Hz} \pm 2.5 \%)$.

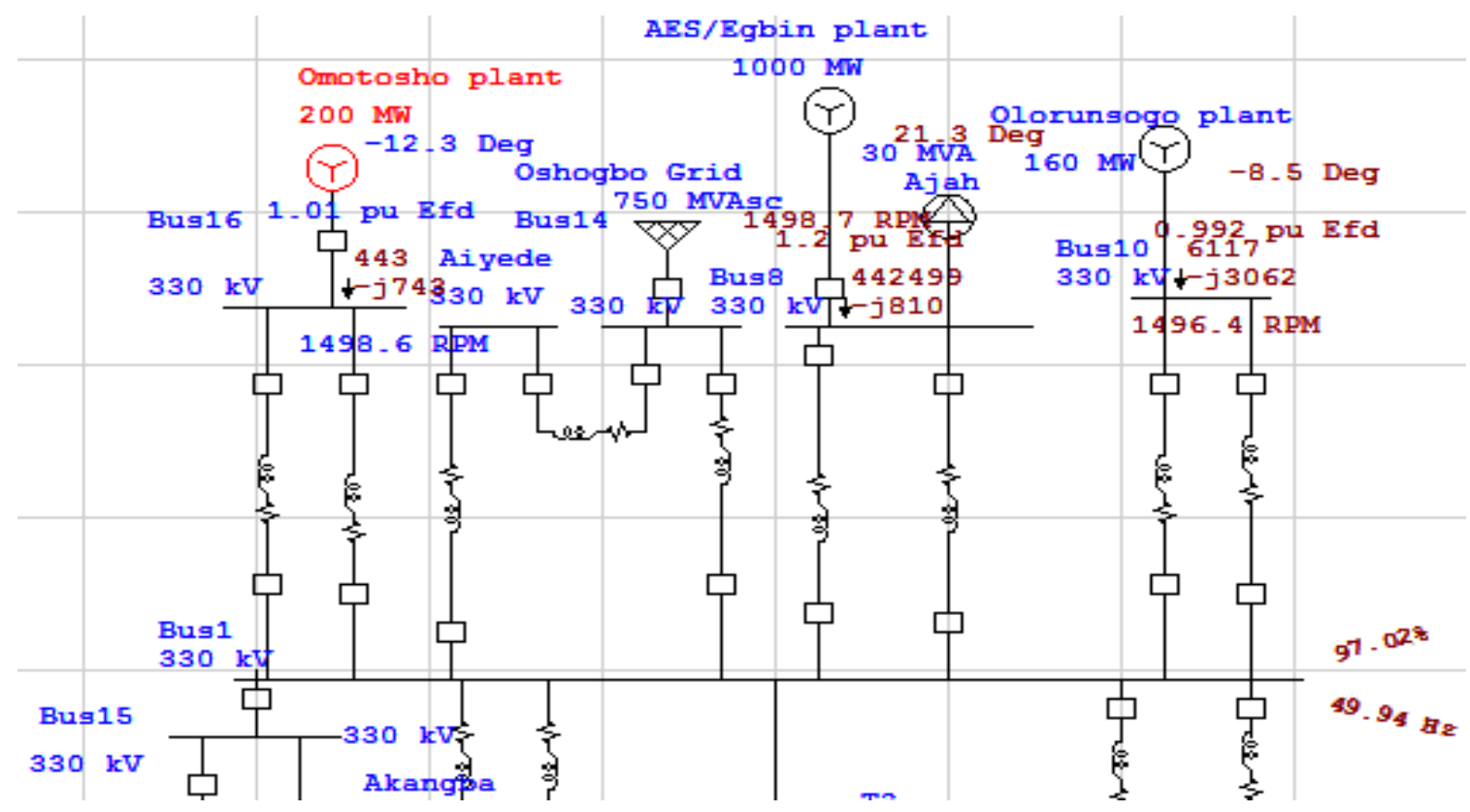

Fig. 2. Event simulated for a transient transmission line fault

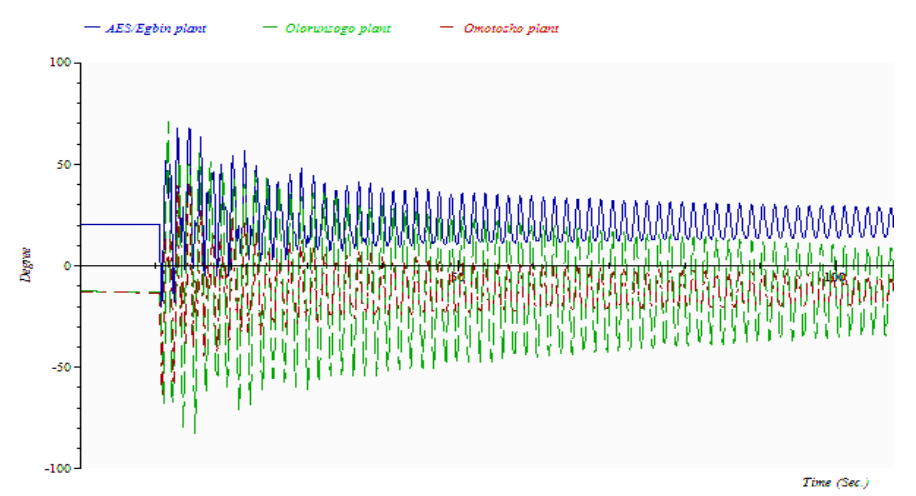

Fig. 3. Power angle of generators after line fault and subsequent clearance

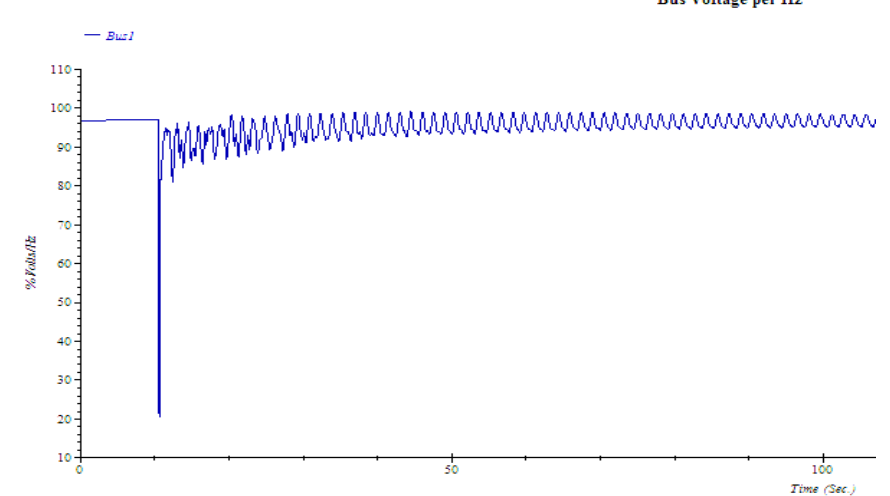

Fig. 4. Ikeja-West sub-station bus-bar voltage/frequency after line fault 


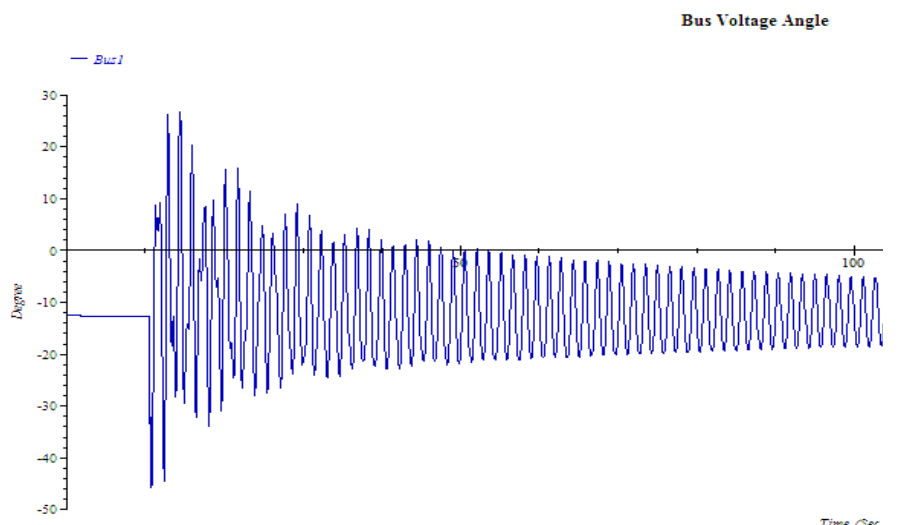

Fig. 5. Ikeja-West bus voltage angle after line fault

However, for a fault that occurred on the EGBIN -IKEJA transmission line at $10.5 \mathrm{~s}$ while its clearance by associated breakers took place at $11.5 \mathrm{~s}$. It would be noticed that the EGBIN generators could only stay in synchronism up to 13.001 seconds (taking a simulation time of 200s) as shown in the Fig. 6. Beyond this time, i.e. at $14 \mathrm{~s}$, (the EGBIN power station lost its synchronism). This suggests that a severe system collapse is imminent except rapid load shedding is carried out (so as) to maintain effective system performance i.e. load generation-load demand balance. The power flow of the system is as shown in Figs. 6 and 7 below. The oscillographic displays (i.e Figs 8 and 9) indicate in small time frames the behavior of the generators before loss of synchronism occurs. When the Grid losses synchronism, the voltage profile and system frequency nose dives to zero which can only be prevented by a rapid load shedding scheme.

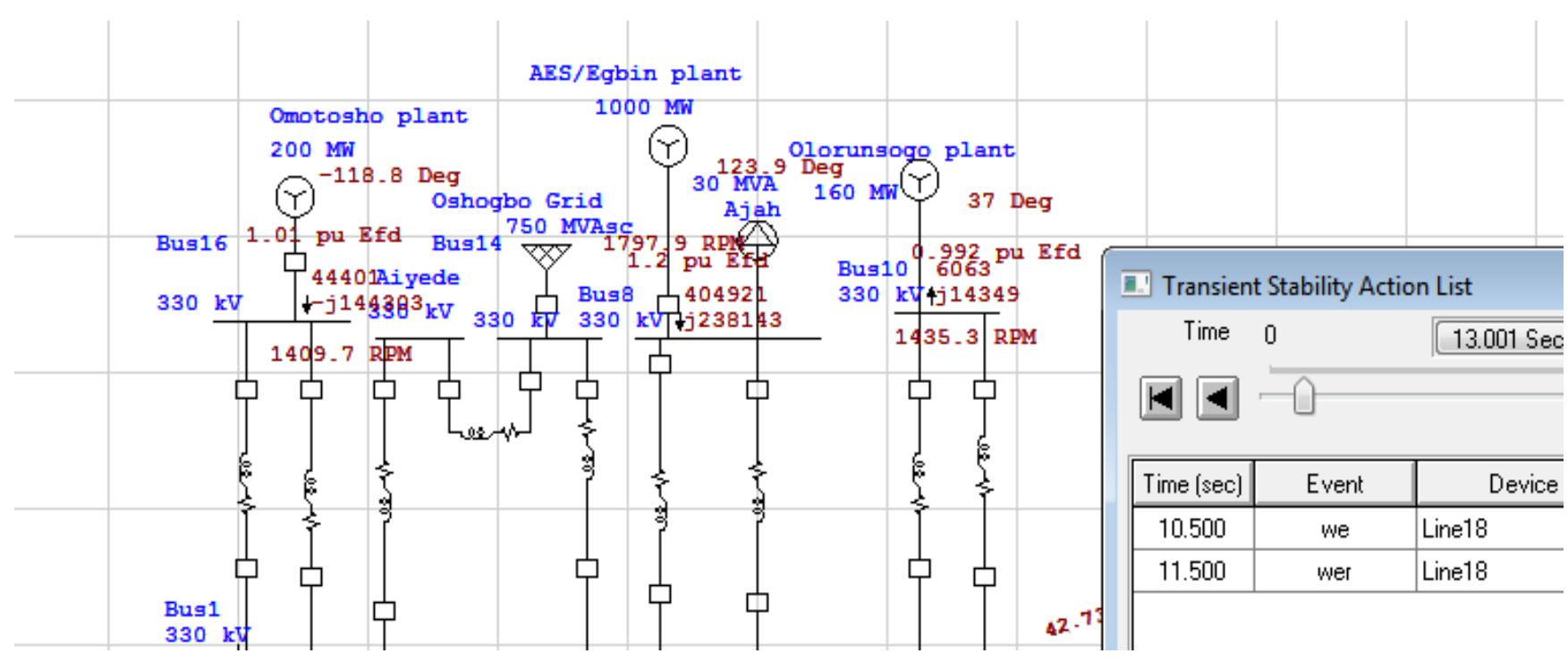

Fig. 6. Event simulated for a sustained transmission line fault

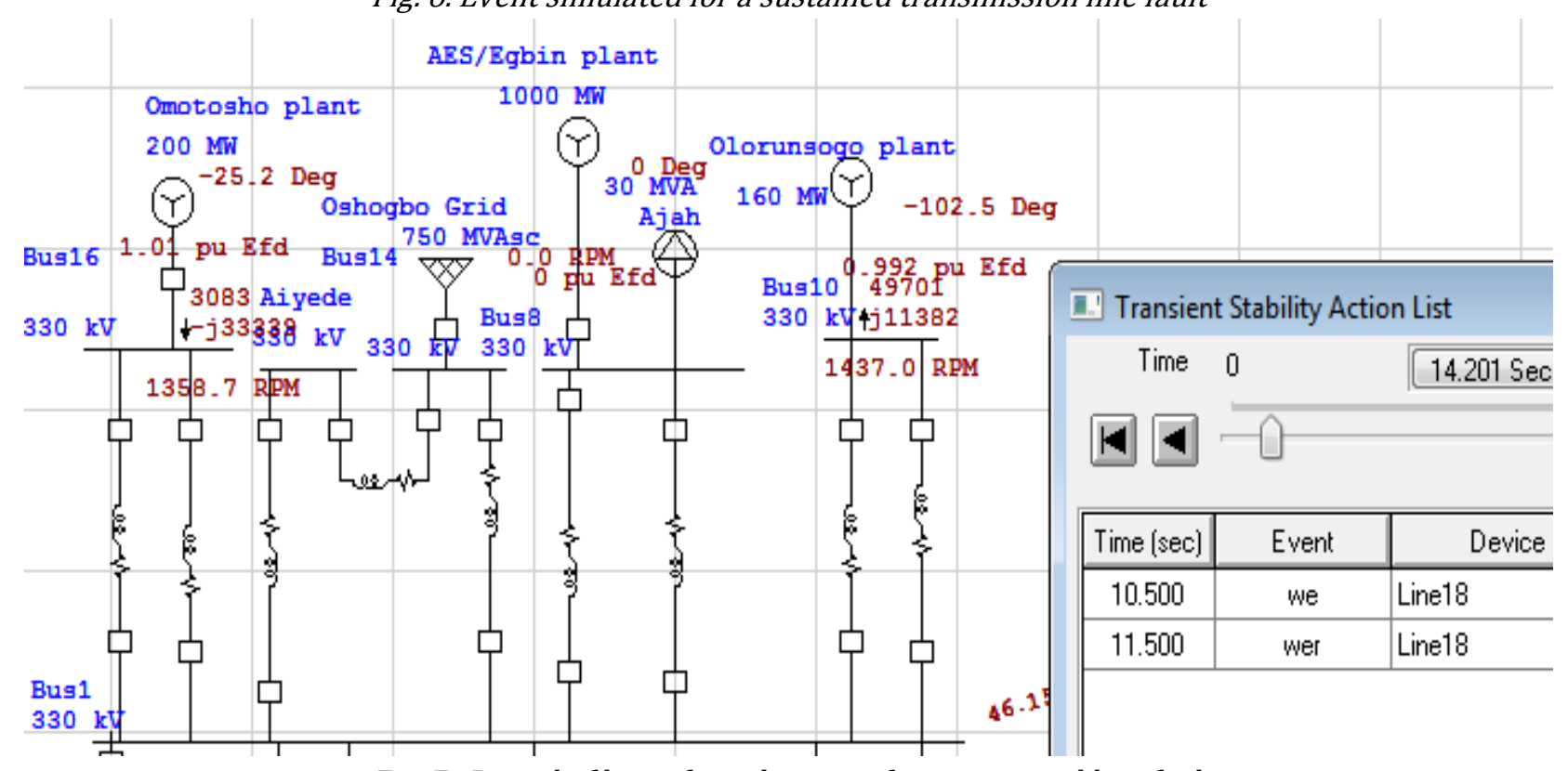

Fig. 7. Period of loss of synchronism for a sustained line fault 
As shown in Figs 8 and 9, the generators have lost synchronism (as stated earlier on), thus the power -angle plot is diverging which could be interpreted as a condition for imminent system collapse. This explains the fact behind the completely shut down of Egbin/AES generators; this is better explained in Fig. 9. The dynamic stability calculation of the system for both the stable and unstable events for this scenario can be found in the Appendices B and C respectively. It accurately represents the change in electrical rotor angle through-out the simulation phase. The exact system parameters of the system when it losses synchronism can be easily seen.

Scenario 2: A three phase fault is created on the IKEJA WEST $330 \mathrm{kV}$ bus bar. The fault is setup to occur at $15.5 \mathrm{~s}$ while its clearance was actuated at $15.6 \mathrm{~s}$ (i.e. the system has $0.1 \mathrm{~s}$ Critical Clearing Time-CCT). The simulation time of 100 s was adopted. As it can be seen in Figs. 10 to Fig. 13 , the system approached stability after the occurrence of fault. Thus the aggregate Generators' rotor angles for the EGBIN, OMOTOSHO and OLORUNSOGO power systems are $20.3 \mathrm{deg},-13.2 \mathrm{deg}$ and $-12.6 \mathrm{deg}$ (respectively) before the occurrence of fault. The rotor angles after the fault occurred are $11.6 \mathrm{deg},-22.2 \mathrm{deg}$ and -42.6 degree respectively (this is as shown in Fig. 10). It was also noted that the grid voltage was $93.49 \%$ of the initial system pre-fault voltage while system frequency is maintained at $49.89 \mathrm{~Hz}$.
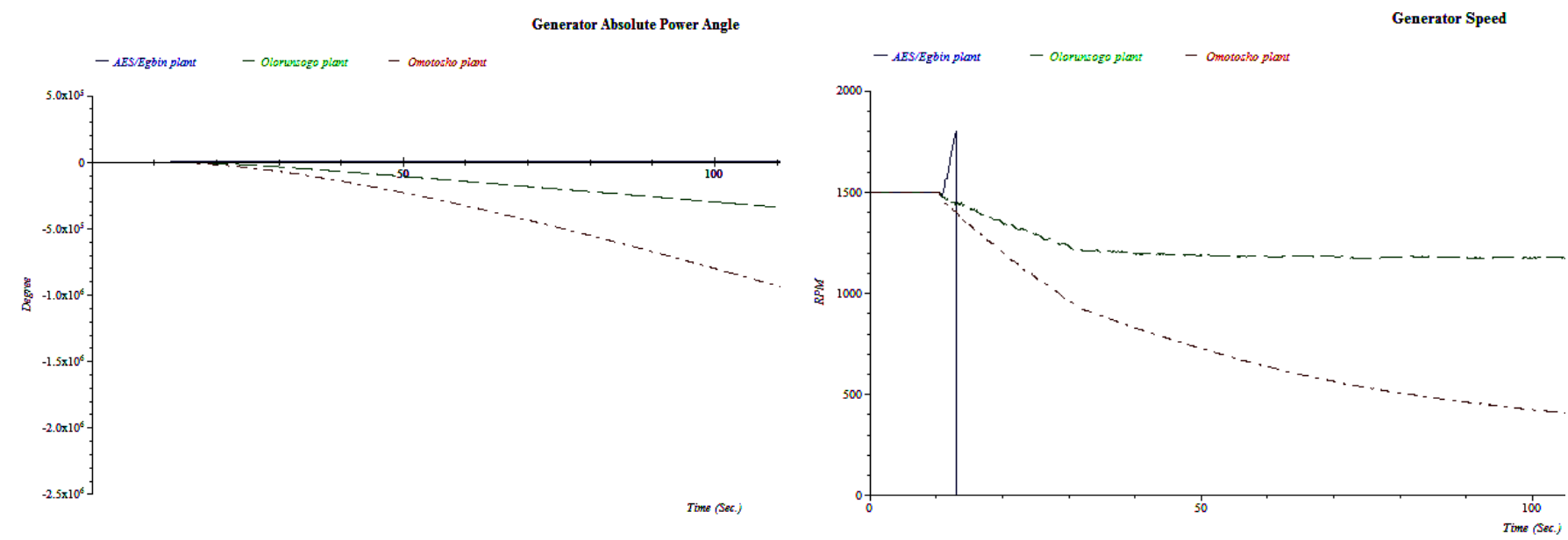

Fig. 8 Loss of synchronism by generator after a sustained line fault

Fig. 9 Generators' rotor speed-time plots after a sustained line fault

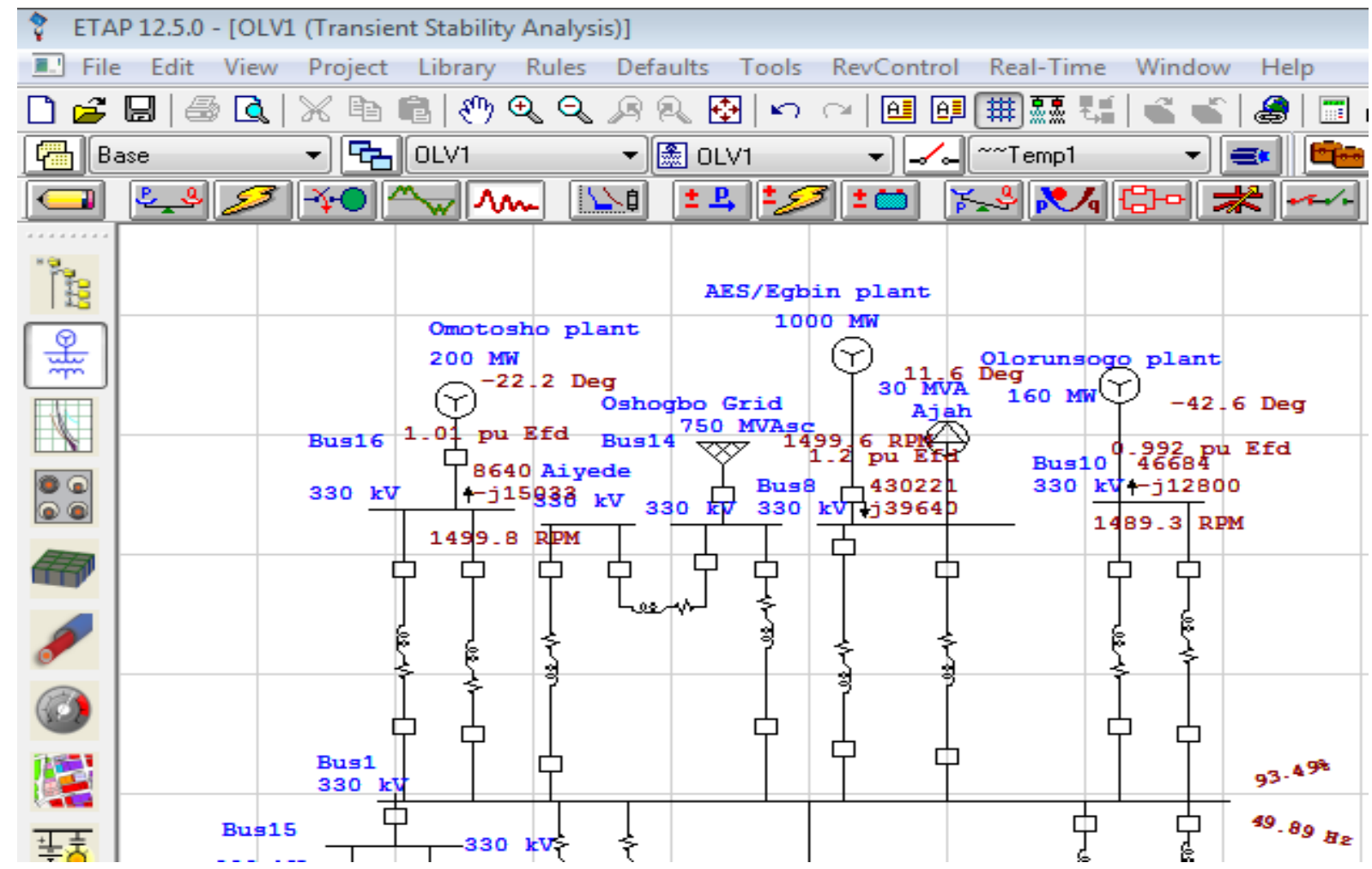

Fig. 10 Fault event simulated for a bus bar fault at Ikeja-West 


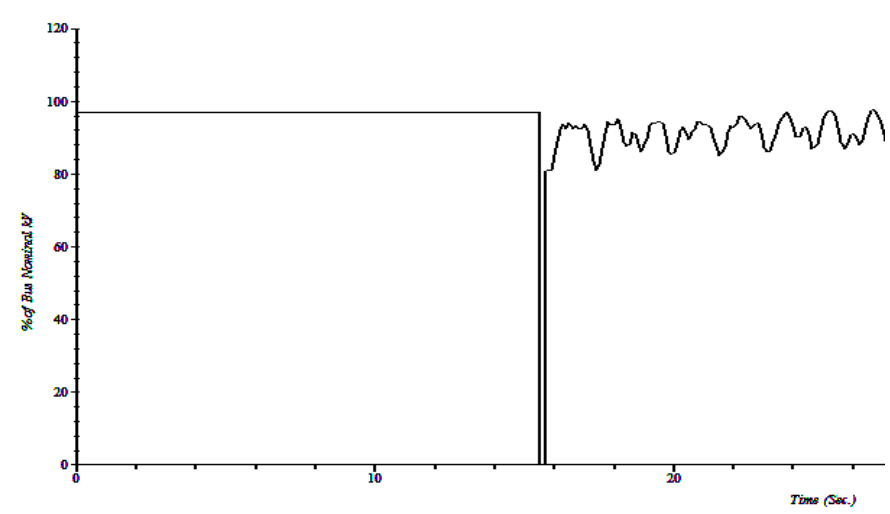

Fig. 11. Bus voltage per hertz after a transient fault on the IkejaWest bus

However, for a critical clearing time of $0.45 \mathrm{~s}$, the EGBIN power generators can only remain in synchronism up to 21.451 seconds (the system lasted for approximately $6 \mathrm{~s}$ before a voltage collapse occurred) as shown in the Fig. 14. Beyond this time, the EGBIN generators were forcibly removed from the system to avoid widespread loss of

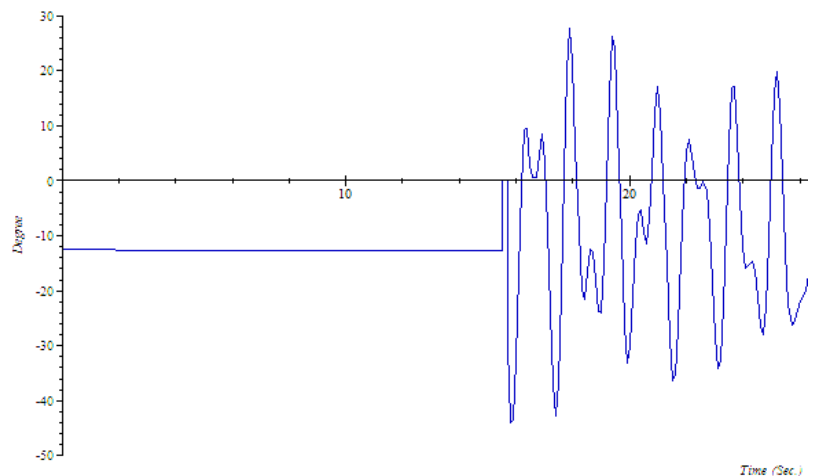

Fig 12. Bus voltage angle after a transient fault on the IkejaWest bus

service. The bus bar voltage at this time dropped to $56.72 \%$ of the nominal value as shown in Fig. 13. The generators' rotor speed -time plots in Fig. 15 visibly display that the AES/Egbin generator have been forced to zero by the fault.

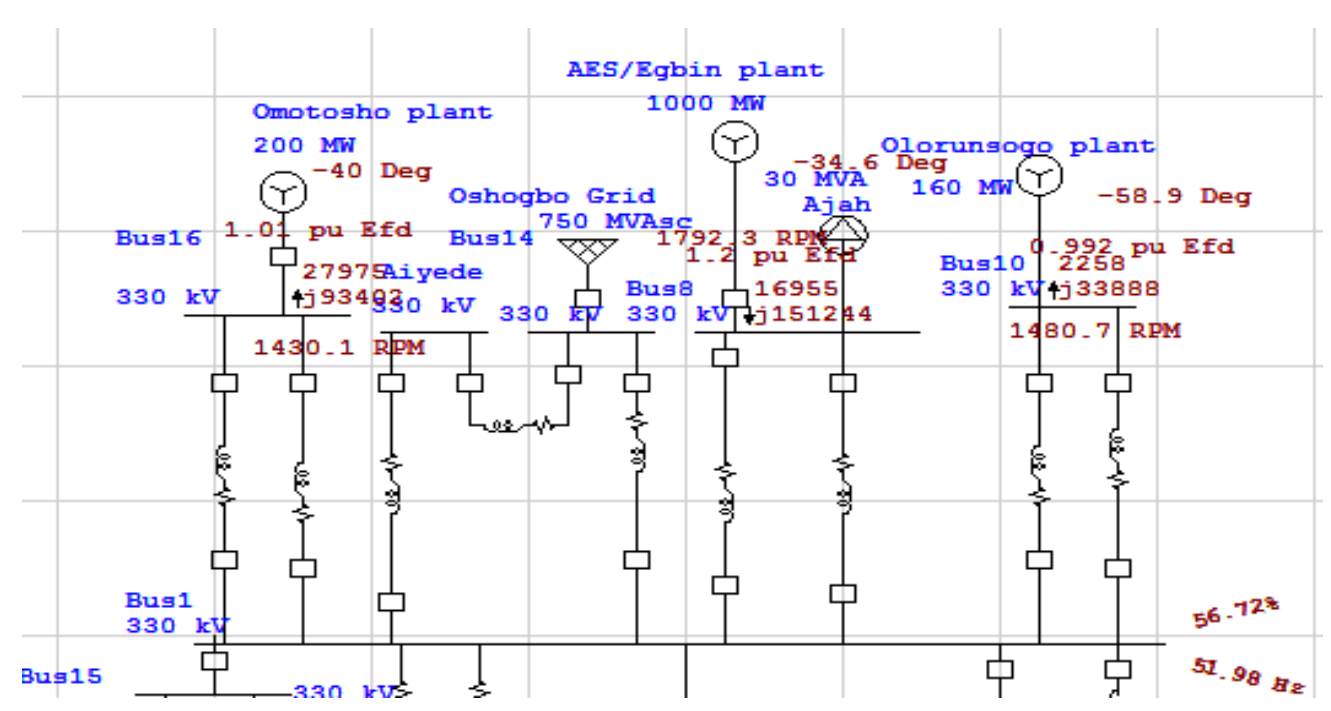

Fig. 13. Instant at which the generators is about to lose synchronism for a sustained bus bar fault

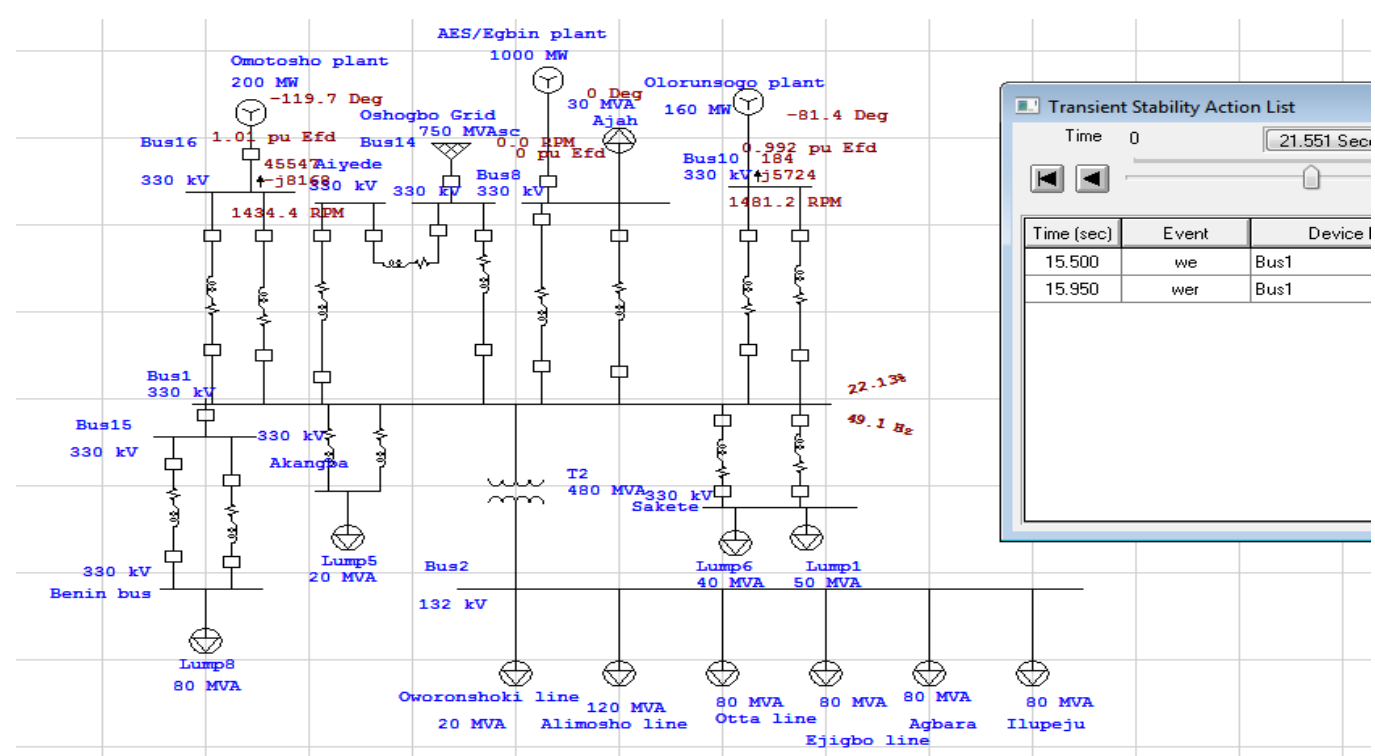

Fig. 14. Instant at which generators just lost synchronism for a sustained bus bar fault 


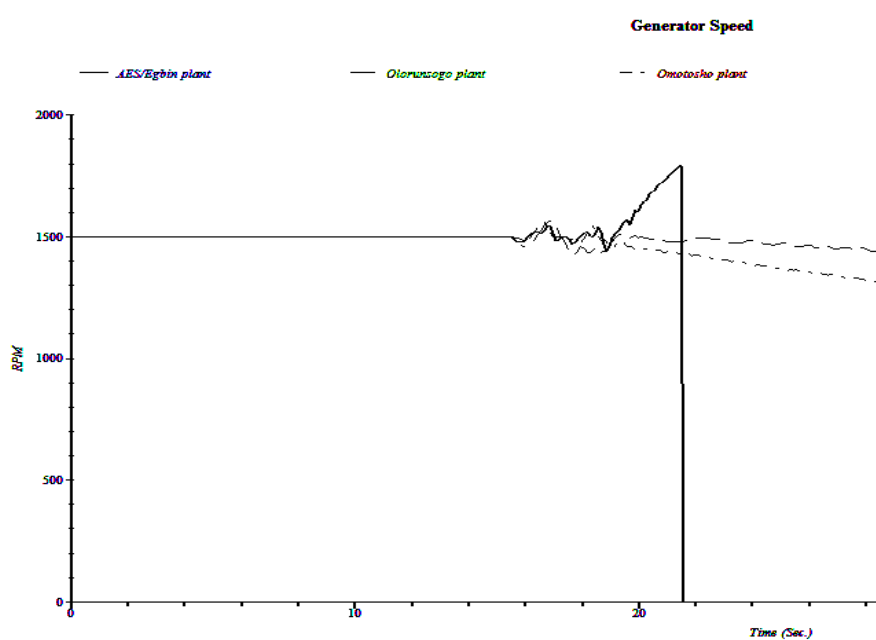

Fig. 15. Generator speed for a sustained bus bar fault

The dynamic stability calculation for the event that made the system unstable in this section is presented in Appendix D. Fluctuations in the disturbed system's electrical rotor angle can be easily seen for selected time period up till when the system lost synchronism leading to an eventual system collapsed.

In a nutshell, for the stability of power system to be maintained after the occurrence of faults, protection systems in the network should clear faults within first $0.2 \mathrm{~s}$ of fault occurrence. This Critical Clearing Time (CCT) was obtained in the simulation presented in scenario 1 and scenario 2 . Thus this is the longest period that a fault could be tolerated in the system before clearance without a possibility of system collapse. At times higher than this, a collapse is imminent except a rapid load shedding sequence is executed to damp the influence of the critical excursion of the system frequency.

\section{CONCLUSION AND RECOMMENDATION}

It can be inferred from the results obtained that the Egbin power plant is critical to the sustenance of the Ikeja West sub-network in the national grid. This is because its forceful removal from the network led to a system collapse. The Egbin/AES power generation system supplies about $33 \%$ of the present power demand thus it is essential to evaluate the sub-network. In other words, the loss of its generating units, unless compensated by adequate spinning reserve from other power generating stations, plunges the system into further swings which eventually results in loss of system synchronism. This phenomenon has been identified during investigations by this research as the major cause of system collapse in Nigeria. Thus the power system collapse in the national grid has been linked to loss of major power stations; which could be any of these three: Egbin, Shiroro or Kainji.
This study has displayed the essence of fast and apt fault clearing in any power system. Thus rapid load shedding schemes using any form of advanced power management system techniques would assist in maintaining the system frequency within acceptable limits; in the event of a loss of supply from a major power station without degrading the service output of the grid.

Meanwhile, transmission lines are most susceptible to faults due to the environmental/topological terrain on which the power transmission tower/steel supports are installed or even adverse weather conditions which in most cases cannot be avoided. With perfectly deployed auto-reclosers in the system, Faulty lines can be restored after a transient fault has been adequately and rapidly cleared. A well-coordinated protection system will ensure that there is no loss of time and an ultimately reliable system.

During the simulation stage of this research work, it was observed that the systems stability was improved when more connection nodes was incorporated in the system. By means of this, power can easily be re-routed from faulty sections to the end users without loss of the system. It is therefore recommended that more loops be created in the transmission sub-network (between buses) for increased reliability and stability during disturbances.

Also, the deployment of faster auto-reclosure mechanisms may facilitate the swinging synchronous generators to develop restoring forces and accentuate the stability limit of the system. Manual reclosure have been considered too sluggish to have any significant impact on the stability limit.

\section{ACKNOWLEDGEMENTS}

The authors of this research work sincerely thank the management and staff of the Transmission Company of Nigeria TCN (Ikeja West 330/132kV sub-station) for the unlimited access to data to ensure accurate modelling of the power system. Also, the management of GIL Automations Limited is appreciated for granting access to the ETAP software for this research work.

\section{REFERENCES}

[1] Sami R., "On-Line voltage stability assessment of power system: an approach of black box modeling", MSc Thesis Institute of Power Engineering Tampere University of Technology, -Unpublished. 2001

[2] Mukherjee A., Kumar Roy P. and Mukherjee V. "Transient stability constrained optimal power flow using oppositional krill herd algorithm" International Journal Electrical Power and Energy Systems 83, March pp 283297, 2016. 
[3] Abdul Wahab N., Mohamed A. and Aini H. "Fast transient stability assessment of large power system using probabilistic neural network with feature reduction techniques", Int. J. Expert Systems with Applications 38, pp. 11112-11119. 2011.

[4] Haidar A., Mustafab M., Ibrahim F. and Ahmed I., "Transient stability evaluation of electrical power system using generalized regression neural networks" Int. J. Applied Soft Computing 11, pp. 3558-3570. 2011.

[5] Hossain M. and Ali M., "Transient stability augmentation of PV/DFIGSG-based hybrid power system by parallelresonance bridge fault current limiter", Int. J. Electric Power Systems Research 130, pp. 89-102 2015.

[6] You D., Wang K., Ye L., Wu J. and Huang R., "Transient stability assessment of power system using support vector machine with generator combinatorial trajectories inputs", Int. J. Electrical Power and Energy Systems 44, September, pp. 318-325. 2012.

[7] Robak S. and Gryszpanowicz K., "Rotor angle small signal stability assessment in transmission network expansion planning", Int. J. Electric Power Systems Research 128 .August 2016 pp. 144-150. 2015.

[8] Su W., Wang J., "Energy Management Systems in Microgrid Operations", The Electricity Journal Vol. 25, October Issue 8. 2012.

[9] Navid G, Haniyeh M., Iman S., "Improvement voltage stability and load ability enhancement by continuation power flow and bifurcation theory", Technical Journal of Engineering and Applied Sciences, pp. 2712-2720. 2013,

[10] Abdelmalik A. A. "Power transformer life management: Relevance to Nigerian power industry" Department of Physics Ahmadu, Bello University, Zaria, Nigeria.

[11] Ezim W. "Nigerian Power Grid has Collapsed 21 times in" http://www.nigeriadailynews.news/news/319356nigerian-power-grid-has-collapsed-21-times-in2016.html Accessed on September 172016

[12] Onohaebi O., "Power outages in the Nigerian transmission grid”, Journal of Applied Sciences 4 (1) pp. 1-9. 2009,

[13] DeMarco C. , Baone C. , Lesieutre B., Han Y., Bose A., Kansal P., Kezunovic M. and Matic-Cuka B. "Control and protection paradigms of the future", Power Systems Engineering Research Center Publication May, pp. 12-10. 2012.

[14] Samuel I., Katende J. and Ibikunle F. "Voltage collapse and the Nigerian National Grid", EIE 2nd International Conference on Computer, Energy, Networking, Robotics and Telecom. 2012.

[15] Izuegbunam F., Ubah C. and Akwukwaegbu I., "Dynamic security assessment of $330 \mathrm{kv}$ Nigerian power system", Academic Research International, Vol. 3, No 1, July 2012.

[16] Abiola A. and Adekilekun T. "Critical clearing time evaluation of Nigerian $330 \mathrm{kV}$ transmission system", American Journal of Electrical Power and Energy Systems; 2(6): October 20, pp. 123-128. 2013.
[17] Khani D., Yazdankhah A. and Kojabadi H. "Impacts of distributed generations on power system transient and voltage stability", Int. J. Electrical Power and Energy Systems 43 p. 488-500. 2012.

[18] Porate K., Thakre K. and Bodhe G. "Voltage stability enhancement of low voltage distribution feeder using Static Var Compensator: a case study", Advanced Applications of Electrical Engineering.

[19] Ghorban A., Khedezadeh M. and Mozafari B. "Impact of SVC on transmission lines", Electric Power and Energy System 42 pp. 702-709. 2012.

[20] Kaurl T. and Kakran S. "Transient Stability Improvement of Long Transmission Line System by Using SVC", International Journal of Advanced Research in Electrical, Electronics and Instrumentation Engineering Vol. 1, Issue 4, October 2012.

[21] Panda S. and Patel R. N., "Improving Power System Transient Stability with an Off-Centre Location of Shunt Facts Devices", Journal of Electrical Engineering, Vol. 57, No. 6, pp. 365-368. 2006.

[22] Kumar A. and Dubey S. B. "Enhancement of Transient Stability in Transmission Line Using SVC Facts Controller", International Journal of Recent Technology and Engineering (IJRTE), Volume-2, Issue-2, May 2013.

[23] Kr Ahuja R. and Chankaya M. "Transient Stability Analysis of Power System with UPFC Using PSAT" International Journal of Emerging Technology and Advanced Engineering Volume 2, Issue 12, December 2012.

[24] Mahdad B. and Srairi K. "Application of a combined superconductor fault current limiter and STATCOM to enhancement of power transient stability", Int. J. Physica C 495 September 2013, pp. 160-168. 2013.

[25] Zadkhast S., Jatskevich J., Vaahedi E. and Alimardani A. "A new adaptive dynamic reduction method for power system transient stability problems, Int. J, Electric Power Systems Research 115, April, pp. 102-110. 2014.

[26] Xia S., Chan K. and Guo Z. "A novel margin sensitivity based method for transient stability constrained optimal flow" Int. J, Electric Power Systems Research 108, November pp. 93-102. 2013

[27] Sulistiawati I., Priyadi A., Qudsi O., Soeprijanto A. and Yorino N. "Critical clearing time prediction within the various loads for transient stability assessment by means of the extreme learning machine method; Int. J, Electrical Power and Energy Systems 77, December, pp. 345-352. 2015.

[28] Wadduwage D., Wu C. and Annakkage U. "Power system transient stability analysis via the concept of Lyapunov exponents" Int. J, Electric Power Systems Research 104, July pp. 183-192. 2014,

[29] Odunsi L. "A comprehensive report on Post Graduate Experience at the IKEJA-WEST 330kV Substation" Report submitted for Registration with the Nigerian Society of Engineers, (Unpublished), 2012. 
Appendix A: Transmission line parameters

\begin{tabular}{llccccc}
\hline S/N & NAME OF LINE & $\begin{array}{l}\text { LENGTH } \\
(\text { Km })\end{array}$ & CONDUCTOR TYPE & $\begin{array}{c}\text { VOLTAGE } \\
\text { LEVEL (kV) }\end{array}$ & Z1 (p.u.) & Z0 (p.u.) \\
\hline 1 & Ikeja west/Benin & 168.5 & 2x350sqmm ACSR & 330 & 0.03513 & 0.10797 \\
2 & Ikeja west/Oshogbo & 92.9 & 2x350sqmm ACSR & 330 & 0.03513 & 0.10797 \\
3 & Ikeja west/Ayede & 85.5 & 2x350sqmm ACSR & 330 & 0.03513 & 0.10797 \\
4 & Ikeja west/sakete & 12.3 & 2x350sqmm ACSR & 330 & 0.03286 & 0.07599 \\
5 & Ikeja west/Akangba 1 & 13.3 & 2x350sqmm ACSR & 330 & 0.0051 & 0.01552 \\
6 & Ikeja west/Olorunsogo & 46 & 2x350sqmm ACSR & 330 & 0.013752 & 0.042221 \\
7 & Ikeja west/Omotosho & 166.5 & 2x350sqmm ACSR & 330 & 0.04469 & 0.15788 \\
& Ikeja west/Egbin & 18.4 & 2x350sqmm ACSR & 330 & 0.02144 & 0.06573 \\
8 & Ikeja west/Oke aro 1 & 17.2 & 2x350sqmm ACSR & 330 & 0.00468 & 0.01587 \\
\hline
\end{tabular}

\section{Appendix B:Scenario 1 Stable Condition}

Dynamic Stability

\begin{tabular}{|c|c|c|c|c|c|c|c|c|c|c|c|c|c|c|c|c|c|}
\hline \multicolumn{18}{|c|}{$\begin{array}{l}\text { Device ID: AES/Egbin plant } \\
\text { Device Type: } \quad \text { Syn. Gen. }\end{array}$} \\
\hline \multirow{2}{*}{\begin{tabular}{|c|} 
Time \\
$(\mathrm{s})$ \\
\end{tabular}} & \multirow{2}{*}{\begin{tabular}{|l|} 
Angle \\
(Deg. $)$ \\
\end{tabular}} & \multirow{2}{*}{\begin{tabular}{|c|} 
Freq. \\
$(\mathrm{Hz})$ \\
\end{tabular}} & \multirow{2}{*}{\begin{tabular}{|l|} 
Mech. \\
MW \\
\end{tabular}} & \multirow{2}{*}{\begin{tabular}{|l|} 
Elec. \\
MW \\
\end{tabular}} & \multirow[b]{2}{*}{ Amp } & \multicolumn{2}{|c|}{ Field (pu) } & \multirow[b]{2}{*}{$\% \mathrm{Z}$} & \multirow{2}{*}{\begin{tabular}{|c|} 
Time \\
$(\mathrm{s})$ \\
\end{tabular}} & \multirow{2}{*}{\begin{tabular}{|l|} 
Angle \\
(Deg.) \\
\end{tabular}} & \multirow{2}{*}{\begin{tabular}{|c|} 
Freq \\
\\
$(\mathrm{Hz})$ \\
\end{tabular}} & \multirow{2}{*}{$\begin{array}{c}\text { Mech. } \\
\text { MW }\end{array}$} & \multirow{2}{*}{$\begin{array}{l}\text { Elec. } \\
\text { MW } \\
\end{array}$} & \multicolumn{3}{|c|}{ Field (pu) } & \multirow{2}{*}{\begin{tabular}{|c|} 
\\
$\% \mathrm{Z}$
\end{tabular}} \\
\hline & & & & & & Ef & Ifd & & & & & & & A & Ef & Ifd & \\
\hline \begin{tabular}{|l|}
15.0010 \\
\end{tabular} & 26.23 & \begin{tabular}{|l|}
49.60 \\
\end{tabular} & 443.239 & 404.691 & 753.6 & 1.20 & 1.15 & 256.7 & 15.1010 & 15.35 & 49.81 & 443.239 & 375.675 & 714.4 & 1.20 & 1.14 & 266.48 \\
\hline \begin{tabular}{|l|}
15.2010 \\
\end{tabular} & 11.75 & 49.97 & \begin{tabular}{|l|}
443.239 \\
\end{tabular} & 419.156 & 795.7 & 1.20 & \begin{tabular}{|l|}
1.19 \\
\end{tabular} & 240.4 & 15.3010 & 10.69 & 49.94 & 443.239 & 470.892 & 889.3 & 1.20 & 1.25 & 216.61 \\
\hline \begin{tabular}{|l|}
15.4010 \\
\end{tabular} & 6.86 & 49.85 & \begin{tabular}{|l|}
443.239 \\
\end{tabular} & 452.193 & 868.2 & 1.20 & 1.25 & 219.4 & 15.5010 & 2.30 & 49.93 & 443.239 & 388.019 & 768.4 & 1.20 & .20 & 242.89 \\
\hline 15.6010 & 4.35 & 50.20 & \begin{tabular}{|l|}
443.239 \\
\end{tabular} & 358.006 & 711.1 & 1.20 & 1.16 & 261.2 & 15.7010 & 15.91 & 50.41 & 443.239 & 401.076 & 766.3 & 1.20 & 1.18 & 248.23 \\
\hline \begin{tabular}{|l|}
15.8010 \\
\end{tabular} & 31.61 & 50.41 & \begin{tabular}{|l|}
443.239 \\
\end{tabular} & 478.041 & 876.3 & 1.20 & 1.22 & 224.4 & 15.9010 & 42.96 & 50.19 & 443.239 & 522.184 & 935.4 & 1.20 & 1.24 & 214.87 \\
\hline \begin{tabular}{|l|}
16.0010 \\
\end{tabular} & 45.35 & 49.96 & 443.239 & 487.498 & 871.1 & \begin{tabular}{|l|}
1.20 \\
\end{tabular} & \begin{tabular}{|l|}
1.19 \\
\end{tabular} & 231.8 & 16.1010 & 42.63 & 49.93 & 443.239 & 419.380 & 758.8 & 1.20 & 1.09 & 265.59 \\
\hline \begin{tabular}{|l|}
16.2010 \\
\end{tabular} & 41.96 & 50.04 & 443.239 & 414.284 & 749.9 & 1.20 & 1.08 & 269.9 & 16.3010 & 43.67 & 50.02 & 443.239 & 484.188 & 858.1 & 1.20 & 1.16 & 238.42 \\
\hline \begin{tabular}{|l|}
16.4010 \\
\end{tabular} & 40.63 & 49.80 & 443.239 & 515.325 & 913.5 & 1.20 & 1.22 & 222.6 & 16.5010 & 29.77 & 49.64 & 443.239 & 457.541 & 832.7 & 1.20 & 1.19 & 237.64 \\
\hline \begin{tabular}{|l|}
16.6010 \\
\end{tabular} & 17.30 & 49.71 & 443.239 & 391.025 & 735.5 & 1.20 & 1.15 & 261.3 & 16.7010 & 10.52 & 49.92 & 443.239 & 380.901 & 727.1 & 1.20 & 1.16 & 261.91 \\
\hline \begin{tabular}{|l|}
16.8010 \\
\end{tabular} & 10.44 & 50.05 & 443 & 429.006 & 808.8 & 1.20 & 1.21 & 238.0 & 16.9010 & 11.80 & 50.00 & .239 & 473.416 & 882.6 & 1.20 & 1.25 & 220.41 \\
\hline \begin{tabular}{|l|}
17.0010 \\
\end{tabular} & 10.09 & 49.92 & \begin{tabular}{|l|}
443.239 \\
\end{tabular} & 445.152 & 838.1 & 1.20 & 1.22 & 230.2 & 17.1010 & 8.29 & 50.01 & 443.239 & 389.235 & 746.8 & 1.20 & 1.18 & 254.46 \\
\hline \begin{tabular}{|l|}
17.2010 \\
\end{tabular} & 12.26 & 50.21 & \begin{tabular}{|l|}
443.239 \\
\end{tabular} & 381.552 & 730.2 & 1.20 & 1.16 & 260.4 & 17.3010 & 22.67 & 50.34 & 443.239 & 429.873 & 799.3 & 1.20 & 1.19 & 243.07 \\
\hline \begin{tabular}{|l|}
17.4010 \\
\end{tabular} & 34.11 & 50.27 & 443.239 & 486.963 & 878.4 & 1.20 & 1.22 & 227.2 & 17.5010 & 40.49 & 50.09 & 443.239 & 490.646 & 872.5 & 1.20 & 1.19 & 232.49 \\
\hline \begin{tabular}{|l|}
17.6010 \\
\end{tabular} & 41.47 & 50.00 & 443.239 & 444.529 & 794.7 & 1.20 & 1.12 & 255.9 & 17.7010 & 41.79 & 50.03 & 443.239 & 427.603 & 767.2 & 1.20 & 1.10 & 265.37 \\
\hline \begin{tabular}{|l|}
17.8010 \\
\end{tabular} & 43.11 & 50.02 & 443.239 & 468.383 & 830.5 & 1.20 & 1.15 & 246.2 & 17.9010 & 41.32 & 49.87 & 443.239 & 496.284 & 879.0 & 1.20 & 1.20 & 231.63 \\
\hline \begin{tabular}{|l|}
18.0010 \\
\end{tabular} & 33.61 & 49.72 & \begin{tabular}{|l|}
443.239 \\
\end{tabular} & 467.595 & 841.3 & 1.20 & 1.19 & 237.9 & 18.1010 & 23.09 & 49.72 & 443.239 & 422.404 & 776.8 & 1.20 & 1.17 & 252.32 \\
\hline \begin{tabular}{|l|}
18.2010 \\
\end{tabular} & 14.76 & 49.83 & \begin{tabular}{|l|}
443.239 \\
\end{tabular} & 405.576 & 758.4 & 1.20 & 1.17 & 255.2 & 18.3010 & 10.49 & 49.93 & 443.239 & 422.148 & 793.1 & 1.20 & 1.20 & 243.63 \\
\hline \begin{tabular}{|l|}
18.4010 \\
\end{tabular} & 8.53 & 49.95 & \begin{tabular}{|l|}
443.239 \\
\end{tabular} & 441.645 & 830.6 & 1.20 & 1.23 & 232.8 & 18.5010 & 6.89 & 49.96 & 443.239 & 430.834 & 816.1 & 1.20 & 1.22 & 235.83 \\
\hline \begin{tabular}{|l|}
18.6010 \\
\end{tabular} & 6.75 & 50.05 & \begin{tabular}{|l|}
443.239 \\
\end{tabular} & 401.958 & 767.2 & 1.20 & \begin{tabular}{|l|}
1.19 \\
\end{tabular} & 249.2 & 18.7010 & 11.10 & 50.20 & 443.239 & 395.301 & 749.3 & 1.20 & 1.18 & 255.98 \\
\hline \begin{tabular}{|l|}
18.8010 \\
\end{tabular} & 20.44 & 50.30 & 443.239 & 426.891 & 791.0 & \begin{tabular}{|l|}
1.20 \\
\end{tabular} & \begin{tabular}{|l|}
1.19 \\
\end{tabular} & 246.5 & 18.9010 & 31.15 & 50.27 & 443.239 & 473.166 & 855.7 & 1.20 & 1.21 & 232.78 \\
\hline
\end{tabular}




\begin{tabular}{|c|c|c|c|c|c|c|c|c|c|c|c|c|c|c|c|c|c|}
\hline \multicolumn{18}{|c|}{$\begin{array}{l}\text { Device ID: } \quad \text { AES/Egbin plant } \\
\text { Device Type: } \quad \text { Syn. Gen. }\end{array}$} \\
\hline \multirow{2}{*}{$\begin{array}{l}\text { Time } \\
\text { (s) }\end{array}$} & \multirow{2}{*}{\begin{tabular}{|l|} 
Angle \\
(Deg.) \\
\end{tabular}} & \multirow{2}{*}{\begin{tabular}{|l} 
Freq. \\
$(\mathrm{Hz})$ \\
\end{tabular}} & \multirow{2}{*}{\begin{tabular}{|c|} 
Mech. \\
MW \\
\end{tabular}} & \multirow{2}{*}{\begin{tabular}{|l|} 
Eec. \\
MW \\
\end{tabular}} & \multirow[b]{2}{*}{ Amp } & \multicolumn{2}{|c|}{ Field (pu) } & & \multirow{2}{*}{$\begin{array}{c}\text { Time } \\
\text { (s) }\end{array}$} & \multirow{2}{*}{$\begin{array}{l}\text { Angle } \\
\text { (Deg.) }\end{array}$} & \multirow{2}{*}{\begin{tabular}{|c|} 
Freq- \\
$(\mathrm{Hz})$ \\
\end{tabular}} & \multirow{2}{*}{\begin{tabular}{|c} 
Mech. \\
MW \\
\end{tabular}} & \multirow{2}{*}{$\begin{array}{l}\text { Elec. } \\
\text { MW }\end{array}$} & \multirow[b]{2}{*}{ Amp } & \multicolumn{2}{|c|}{ Field (pu) } & \multirow{2}{*}{\begin{tabular}{|l|l} 
& \\
& \\
$\% \mathbf{Z}$
\end{tabular}} \\
\hline & & & & & & \begin{tabular}{|l|} 
Ffd \\
\end{tabular} & Ifd & $\% \mathrm{Z}$ & & & & & & & \begin{tabular}{|l|} 
Ffd \\
\end{tabular} & \begin{tabular}{|l|} 
Ifd \\
\end{tabular} & \\
\hline 9.6000 & 20.13 & 50.00 & 443.239 & 441.590 & 771.9 & 1.20 & 1.20 & 266.86 & 9.7000 & 20.13 & 50.00 & $\begin{array}{c}1 \\
443.239\end{array}$ & 441.592 & $\begin{array}{l}771.9 \\
77\end{array}$ & 1.20 & 1.20 & 266.86 \\
\hline 9.8000 & 20.13 & 50.00 & \begin{tabular}{|l|}
443.239 \\
\end{tabular} & \begin{tabular}{|l|}
441.588 \\
\end{tabular} & \begin{tabular}{l|}
771.9 \\
\end{tabular} & 1.20 & 1.20 & \begin{tabular}{|l|}
266.87 \\
\end{tabular} & 9.9000 & 20.13 & 50.00 & 443.239 & 441.588 & 771.9 & 1.20 & 1.20 & 266.87 \\
\hline 10.0000 & 20.12 & 50.00 & 443.239 & 441.593 & 771.9 & 1.20 & 1.20 & 266.87 & 10.1000 & 20.12 & 50.00 & 443.239 & 441.589 & 771.9 & 1.20 & 1.20 & 266.87 \\
\hline 10.2000 & 20.12 & 50.00 & 443.239 & 441.576 & 771.9 & 1.20 & 1.20 & 266.88 & 10.3000 & 20.12 & 50.00 & 444.239 & 441.571 & 771.9 & 1.20 & 1.20 & 266.88 \\
\hline 10.4000 & 20.12 & 50.00 & 443.239 & 441.578 & \begin{tabular}{l|}
771.9 \\
\end{tabular} & 1.20 & 1.20 & 266.88 & 10.5000 & 20.12 & 50.00 & 443.239 & 441.586 & 771.9 & 1.20 & 1.20 & 266.88 \\
\hline 10.7010 & -9.45 & \begin{tabular}{l|}
49.34 \\
\end{tabular} & 443.239 & 424.598 & \begin{tabular}{l|}
4344.1 \\
\end{tabular} & 1.20 & 3.53 & \begin{tabular}{l|}
14.27 \\
\end{tabular} & 10.8010 & -33.92 & 49.34 & 443.239 & 372.046 & 4171.5 & 1.20 & 3.38 & 14.02 \\
\hline $\begin{array}{l}10.9010 \\
\end{array}$ & -55.33 & 49.49 & $\begin{array}{l}443.239 \\
\end{array}$ & 339.736 & \begin{tabular}{|l|}
4039.7 \\
\end{tabular} & 1.20 & 3.27 & 13.61 & 11.0010 & \begin{tabular}{l|l|}
-69.48 \\
\end{tabular} & 499.73 & 443.239 & 322.116 & 3940.6 & \begin{tabular}{|l|}
5 \\
\end{tabular} & 3.18 & 13.07 \\
\hline 11.1010 & -74.02 & 50.03 & 443.239 & 301.943 & 3864.5 & 1.20 & 3.10 & 12.30 & 11.2010 & -66.39 & 50.42 & 443.239 & 257.082 & 3772.1 & 1.20 & 3.02 & 11.41 \\
\hline 11.3010 & -41.41 & 51.00 & 443.239 & 192.298 & \begin{tabular}{|l|}
3564.3 \\
\end{tabular} & 1.20 & 2.86 & 11.51 & 11.4010 & 7.35 & 51.70 & 443.239 & 196.001 & 3277.8 & 1.20 & 2.66 & 13.61 \\
\hline 11.5000 & 78.32 & 52.24 & 443.239 & 257.717 & 3291.8 & 1.20 & 2.65 & 13.30 & 11.5010 & \begin{tabular}{l|}
79.12 \\
\end{tabular} & 52.23 & 443.239 & 507.848 & 1256.1 & 1.20 & \begin{tabular}{|l|}
1.26 \\
\end{tabular} & 116.75 \\
\hline 11.6010 & 147.08 & 51.65 & 443.239 & 448.308 & 1777.1 & 1.20 & 1.67 & 59.77 & 11.7010 & -152.20 & 51.86 & 443.239 & 180.877 & 1696.4 & 1.20 & \begin{tabular}{|l|}
1.65 \\
\end{tabular} & 49.16 \\
\hline 11.8010 & -67.33 & 52.88 & 443.239 & 32.179 & \begin{tabular}{l|}
1236.3 \\
\end{tabular} & 1.20 & 1.37 & 73.08 & 11.9010 & 60.09 & 53.97 & 443.239 & 402.442 & 1053.8 & 1.20 & \begin{tabular}{|l|}
1.11 \\
\end{tabular} & 131.93 \\
\hline 12.0010 & -160.24 & 53.87 & 443.239 & 202.797 & 1828.5 & 1.20 & 1.73 & 43.92 & 12.1010 & \begin{tabular}{|c|}
-1.63 \\
\end{tabular} & 54.85 & 443.239 & 198.713 & 1005.8 & $\begin{array}{ll}1.20 \\
\end{array}$ & 1.20 & 106.29 \\
\hline 12.6010 & -15.14 & 57.07 & 443.239 & 116.048 & 540.0 & 1.20 & 0.84 & 193.55 & 12.7010 & -113.11 & 57.50 & 443.239 & 177.611 & 1339.4 & 1.20 & 1.36 & 62.02 \\
\hline 12.8010 & 171.01 & 58.14 & 443.239 & 490.944 & 1583.6 & 1.20 & 1.43 & 72.65 & 12.9010 & \begin{tabular}{|l|}
113.72 \\
\end{tabular} & 58.78 & 443.239 & 499.174 & 1283.5 & 1.20 & 1.16 & 109.16 \\
\hline 13.0010 & 73.58 & 59.26 & 443.239 & 405.005 & 1058.6 & 1.20 & 1.02 & 130.19 & 13.1010 & \begin{tabular}{|l|}
49.72 \\
\end{tabular} & 59.67 & 443.239 & 325.109 & 969.0 & 1.20 & \begin{tabular}{|l|}
1.03 \\
\end{tabular} & 127.25 \\
\hline 13.2010 & 0.00 & 0.00 & 0.000 & 0.000 & 0.0 & 0.00 & 0.00 & 0.00 & 13.3010 & 0.00 & 0.00 & 0.000 & 0.000 & 0.0 & 0.00 & 0.00 & 0.00 \\
\hline 13.4010 & 0.00 & 0.00 & 0.000 & 0.000 & 0.0 & 0.00 & 0.00 & 0.00 & 13.5010 & 0.00 & 0.00 & 0.000 & 0.000 & 0.0 & 0.00 & 0.00 & 0.00 \\
\hline 13.6010 & 0.00 & 0.00 & 0.000 & 0.000 & 0.0 & 0.00 & 0.00 & 0.00 & 13.7010 & 0.00 & 0.00 & 0.000 & 0.000 & 0.0 & 0.00 & 0.00 & 0.00 \\
\hline 13.8010 & 0.00 & 0.00 & 0.000 & 0.000 & 0.0 & 0.00 & 0.00 & 0.00 & 13.9010 & 0.00 & 0.00 & 0.000 & 0.000 & 0.0 & 0.00 & 0.00 & 0.00 \\
\hline 14.0010 & 0.00 & 0.00 & 0.000 & 0.000 & 0.0 & 0.00 & 0.00 & 0.00 & 14.1010 & 0.00 & 0.00 & 0.000 & 0.000 & 0.0 & 0.00 & 0.00 & 0.00 \\
\hline 14.2010 & 0.00 & 0.00 & 0.000 & 0.000 & 0.0 & 0.00 & 0.00 & 0.00 & 14.3010 & 0.00 & 0.00 & 0.000 & 0.000 & 0.0 & 0.00 & 0.00 & 0.00 \\
\hline 14.4010 & 0.00 & 0.00 & 0.000 & 0.000 & 0.0 & 0.00 & 0.00 & 0.00 & 14.5010 & 0.00 & 0.00 & 0.000 & 0.000 & 0.0 & 0.00 & 0.00 & 0.00 \\
\hline 14.6010 & 0.00 & 0.00 & 0.000 & 0.000 & 0.0 & 0.00 & 0.00 & 0.00 & 14.7010 & 0.00 & 0.00 & 0.000 & 0.000 & 0.0 & 0.00 & 0.00 & 0.00 \\
\hline 14.8010 & 0.00 & 0.00 & 0.000 & 0.000 & 0.0 & 0.00 & 0.00 & 0.00 & 14.9010 & 0.00 & 0.00 & 0.000 & 0.000 & 0.0 & 0.00 & 0.00 & 0.00 \\
\hline 15.0010 & 0.00 & 0.00 & 0.000 & 0.000 & 0.0 & 0.00 & 0.00 & 0.00 & 15.1010 & 0.00 & 0.00 & 0.000 & 0.000 & 0.0 & 0.00 & 0.00 & 0.00 \\
\hline 15.2010 & 0.00 & 0.00 & 0.000 & 0.000 & 0.0 & 0.00 & 0.00 & 0.00 & 15.3010 & 0.00 & 0.00 & 0.000 & 0.000 & 0.0 & 0.00 & 0.00 & 0.00 \\
\hline 15.4010 & 0.00 & 0.00 & 0.000 & 0.000 & 0.0 & 0.00 & 0.00 & 0.00 & 15.5010 & 0.00 & 0.00 & 0.000 & 0.000 & 0.0 & 0.00 & 0.00 & 0.00 \\
\hline
\end{tabular}

Appendix B: Scenario 2-Unstable Condition

\begin{tabular}{|c|c|c|c|c|c|c|c|c|c|c|c|c|c|c|c|c|c|}
\hline \multicolumn{18}{|c|}{$\begin{array}{l}\text { Device ID: AES/Egbin plant } \\
\text { Device Type: } \quad \text { Syn. Gen. }\end{array}$} \\
\hline Time & Angle & Freq. & Mech. & Elec & & \multicolumn{2}{|c|}{ Field (pu) } & & Time & Angle & Fre & Mech. & Elec. & & \multicolumn{2}{|c|}{ Field $(\mathrm{pu})$} & \\
\hline 15.0000 & 20.10 & 50.00 & 443.239 & \begin{tabular}{|l|}
1 \\
441.582 \\
\end{tabular} & 771.8 & 1.20 & 1.20 & 266.94 & 15.1000 & 20.10 & 50.00 & 443.239 & 441.585 & 771.8 & 1.20 & 1.20 & 266.94 \\
\hline 15.2000 & 20.10 & 50.00 & 443.239 & 441.590 & 771.8 & 1.20 & 1.20 & 266.94 & 15.3000 & 20.10 & 50.00 & 443.239 & 441.589 & 771.8 & 1.20 & 1.20 & 266.94 \\
\hline 15.4000 & 20.10 & 50.00 & 443.239 & 441.581 & 771.8 & 1.20 & 1.20 & 266.94 & 15.5000 & 20.10 & 50.00 & 443.239 & 441.578 & 771.8 & 1.20 & 1.20 & 266.95 \\
\hline 15.7010 & -5.65 & 49.39 & 443.239 & 446.980 & 4150.1 & 1.20 & 3.41 & 16.60 & 15.8010 & \begin{tabular}{|c|}
-29.78 \\
\end{tabular} & 49.29 & 443.239 & 412.836 & 3988.4 & 1.20 & 3.28 & 16.60 \\
\hline 15.9010 & -55.06 & 49.32 & 443.239 & 381.958 & 3836.4 & 1.20 & 3.15 & 16.60 & 15.9500 & -66.59 & 49.37 & 443.239 & 367.928 & 3765.3 & 1.20 & 3.09 & 16.60 \\
\hline 15.9510 & -66.81 & 49.38 & 443.239 & 263.626 & 1162.3 & 1.20 & 1.46 & 117.15 & 16.0510 & \begin{tabular}{l|l}
-77.79 \\
\end{tabular} & 49.95 & 443.239 & 320.963 & 1270.4 & 1.20 & 1.52 & 107.29 \\
\hline 16.1510 & -73.84 & 50.24 & 443.239 & 367.454 & 1479.2 & 1.20 & 1.64 & 88.80 & 16.2510 & -61.64 & 50.42 & 443.239 & 396.994 & 1473.7 & 1.20 & 1.63 & 90.37 \\
\hline 16.3510 & -45.06 & 50.49 & 443.239 & \begin{tabular}{|l|}
422.062 \\
\end{tabular} & 1356.6 & 1.20 & 1.53 & 103.14 & 16.4510 & -26.01 & 50.60 & 443.239 & 369.189 & 1094.0 & 1.20 & 1.35 & 133.26 \\
\hline 16.5510 & 0.79 & 50.90 & 443.239 & 334.456 & 827.2 & 1.20 & 1.15 & 189.02 & 16.6510 & 38.84 & 51.18 & 443.239 & 378.804 & 786.9 & 1.20 & 1.03 & 220.37 \\
\hline 16.7510 & 82.27 & $\begin{array}{l}51.16 \\
\end{array}$ & 443.239 & \begin{tabular}{|l|}
520.867 \\
\end{tabular} & 1040.5 & 1.20 & 1.19 & 173.25 & 16.8510 & 113.08 & 50.49 & 443.239 & 664.027 & 1319.1 & 1.20 & 1.39 & 137.58 \\
\hline 17.1510 & 128.57 & 50.39 & 443.239 & 424.611 & 1046.8 & 1.20 & 1.28 & 149.98 & 17.2510 & 138.77 & 50.03 & 443.239 & 695.749 & 1450.2 & 1.20 & 1.49 & 120.36 \\
\hline 17.3510 & 119.50 & 48.85 & 443.239 & 804.425 & 1585.7 & 1.20 & 1.56 & 115.43 & 17.4510 & 62.96 & 48.29 & 443.239 & 413.960 & 851.1 & 1.20 & 1.04 & 206.42 \\
\hline 17.5510 & 11.40 & 48.98 & 443.239 & 145.274 & 330.8 & 1.20 & 0.79 & 480.82 & 17.6510 & \begin{tabular}{|c|}
-6.87 \\
\end{tabular} & 49.98 & 443.239 & 196.765 & 468.1 & 1.20 & 0.92 & 335.08 \\
\hline
\end{tabular}


Device ID: AES/Egbin plant

Device Type: Syn. Gen.

\begin{tabular}{|c|c|c|c|c|c|c|c|c|c|c|c|c|c|c|c|c|c|}
\hline Time & Angle & Freq. & Mech. & Elec & & \multicolumn{2}{|c|}{ Field (pu) } & & Time & Angle & Fre & Mech. & Elec. & & \multicolumn{2}{|c|}{ Field (pu) } & \\
\hline (s) & (Deg.) & $(\mathrm{Hz})$ & MW & $\mathrm{M}$ & Amp & Efd & Ifd & $\% \mathrm{Z}$ & (s) & (Deg.) & $(\mathrm{Hz})$ & MW & MW & Amp & Efd & Ifd & $\% \mathrm{Z}$ \\
\hline 21.3510 & 40.82 & 57.34 & 443.239 & 240.956 & 595.2 & 1.20 & 0.87 & 245.33 & 21.4510 & -63.48 & 57.22 & 443.239 & -108.839 & 824.5 & 1.20 & 1.19 & 145.87 \\
\hline 21.5510 & -156.23 & 57.15 & 443.239 & 316.977 & 2320.9 & 1.20 & 2.10 & 36.18 & 21.6510 & 117.57 & 57.71 & 443.239 & 764.332 & 1917.6 & 1.20 & 1.72 & 76.16 \\
\hline 21.7510 & 37.31 & 58.15 & 443.239 & 321.793 & 852.1 & 1.20 & 1.05 & 165.63 & 21.8510 & -32.28 & 58.33 & 443.239 & 78.534 & 564.9 & 1.20 & 1.00 & 217.67 \\
\hline 21.9510 & -90.59 & 58.45 & 443.239 & -24.424 & 1126.9 & 1.20 & 1.38 & 95.29 & 22.0510 & -138.09 & 58.57 & 443.239 & 140.480 & 1960.2 & 1.20 & 1.89 & 43.90 \\
\hline 22.1510 & -176.66 & 58.81 & 443.239 & 634.131 & 2352.9 & 1.20 & 2.07 & 46.27 & 22.2510 & 151.57 & 59.14 & 443.239 & 824.215 & 2109.5 & 1.20 & 1.84 & 67.85 \\
\hline 22.3510 & 125.20 & 59.41 & 443.239 & 740.562 & 1756.2 & 1.20 & 1.60 & 87.13 & 22.4510 & 104.15 & 59.63 & 443.239 & 639.172 & 1470.6 & 1.20 & 1.40 & 106.77 \\
\hline 22.5510 & 89.47 & 59.83 & 443.239 & 577.506 & 1335.3 & 1.20 & 1.30 & 116.88 & 22.6510 & 0.00 & 0.00 & 0.000 & 0.000 & 0.0 & 0.00 & 0.00 & 0.00 \\
\hline 22.7510 & 0.00 & 0.00 & 0.000 & 0.000 & 0.0 & 0.00 & 0.00 & 0.00 & 22.8510 & 0.00 & 0.00 & 0.000 & 0.000 & 0.0 & 0.00 & 0.00 & 0.00 \\
\hline 22.9510 & 0.00 & 0.00 & 0.000 & 0.000 & 0.0 & 0.00 & 0.00 & 0.00 & 23.0510 & 0.00 & 0.00 & 0.000 & 0.000 & 0.0 & 0.00 & 0.00 & 0.00 \\
\hline 23.1510 & 0.00 & 0.00 & 0.000 & 0.000 & 0.0 & 0.00 & 0.00 & 0.00 & 23.2510 & 0.00 & 0.00 & 0.000 & 0.000 & 0.0 & 0.00 & 0.00 & 0.00 \\
\hline 23.3510 & 0.00 & 0.00 & 0.000 & 0.000 & 0.0 & 0.00 & 0.00 & 0.00 & 23.4510 & 0.00 & 0.00 & 0.000 & 0.000 & 0.0 & 0.00 & 0.00 & 0.00 \\
\hline 23.5510 & 0.00 & 0.00 & 0.000 & 0.000 & 0.0 & 0.00 & 0.00 & 0.00 & 23.6510 & 0.00 & 0.00 & 0.000 & 0.000 & 0.0 & 0.00 & 0.00 & 0.00 \\
\hline 23.7510 & 0.00 & 0.00 & 0.000 & 0.000 & 0.0 & 0.00 & 0.00 & 0.00 & 23.8510 & 0.00 & 0.00 & 0.000 & 0.000 & 0.0 & 0.00 & 0.00 & 0.00 \\
\hline 23.9510 & 0.00 & 0.00 & 0.000 & 0.000 & 0.0 & 0.00 & 0.00 & 0.00 & 24.0510 & 0.00 & 0.00 & 0.000 & 0.000 & 0.0 & 0.00 & 0.00 & 0.00 \\
\hline
\end{tabular}

Appendix D: Generator Parameters

Synchronous Generator Input Data

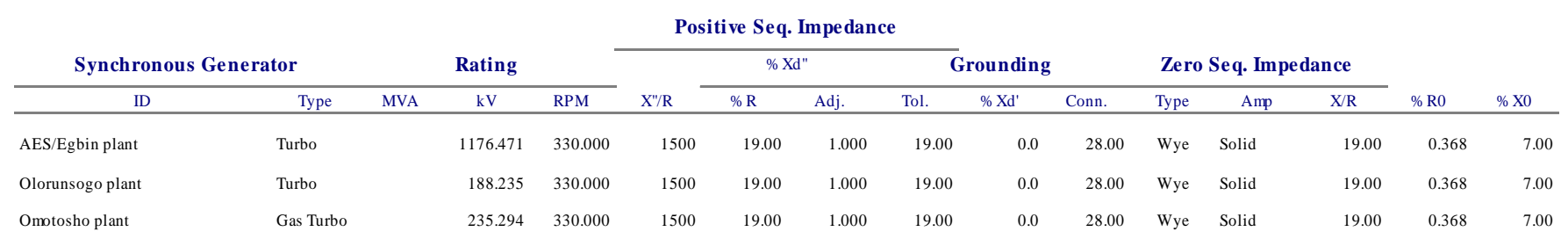

Total Connected Synchronous Generators ( $=3$ ): 1600.000 MVA

Appendix E: Load Parameters

Lumped Load Input Data

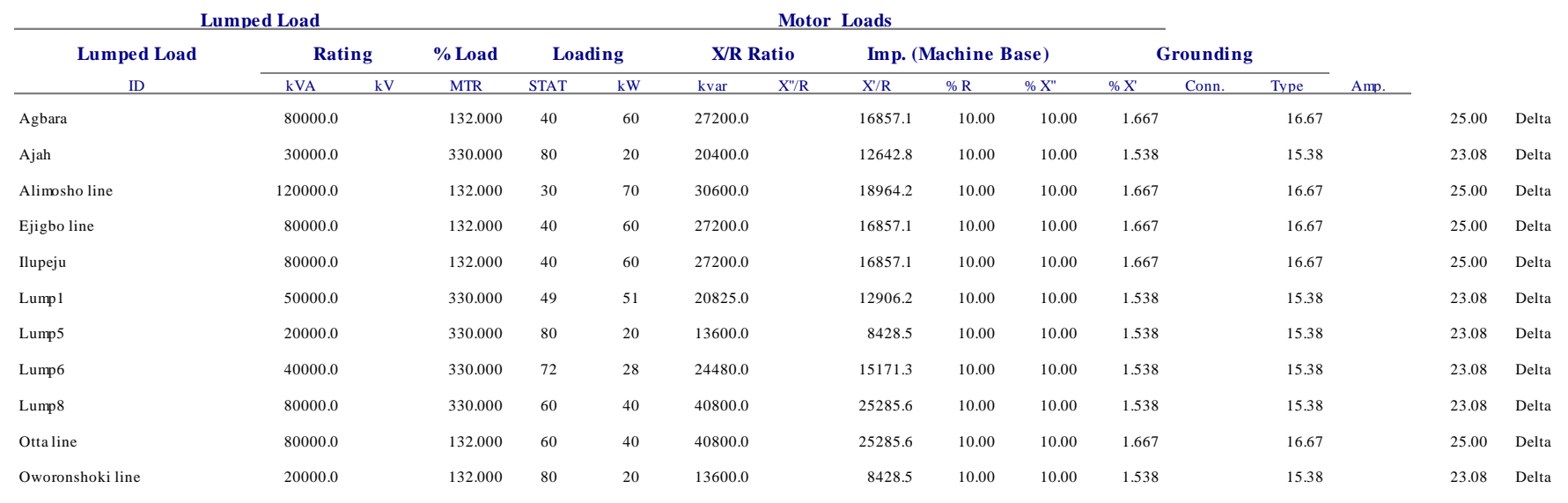


Appendix F: Line Loading

$\underline{\text { Line/Cable Input Data }}$

Ohms or Siemens per $1000 \mathrm{ft}$ per Conductor (Cable) or per Phase (Line)

\begin{tabular}{|c|c|c|c|c|c|c|c|c|c|c|c|c|}
\hline \multirow{3}{*}{$\begin{array}{c}\text { Line/Cable } \\
\text { ID }\end{array}$} & \multirow{2}{*}{\multicolumn{4}{|c|}{ Length }} & \multirow[b]{4}{*}{ \#/Phase } & \multirow[b]{4}{*}{$\mathrm{T}\left({ }^{\circ} \mathrm{C}\right)$} & \multirow[b]{4}{*}{ R1 } & & \multirow[b]{4}{*}{ Y1 } & \multirow[b]{4}{*}{ R0 } & & \multirow[b]{4}{*}{ Y0 } \\
\hline & & & & & & & & \multirow[b]{3}{*}{$\mathrm{X} 1$} & & & \multirow[b]{3}{*}{$\mathrm{X} 0$} & \\
\hline & \multicolumn{2}{|l|}{ Library } & Size & Adj. (ft) & & & & & & & & \\
\hline & & & & $\%$ Tol. & & & & & & & & \\
\hline Egbin line & $\mathbf{F}$ & 250 & 203412.1 & 0.0 & 1 & 75 & 0.0847886 & 0.1253539 & 0.0000009 & 0.1594664 & 0.4187237 & 0.0000004 \\
\hline Egbin line 2 & $\boldsymbol{F}$ & 250 & 203412.1 & 0.0 & 1 & 75 & 0.0847886 & 0.1253539 & 0.0000009 & 0.1594664 & 0.4187237 & 0.0000004 \\
\hline Line1 & $\boldsymbol{F}$ & 267 & 55774.3 & 0.0 & 1 & 75 & 0.0802177 & 0.1207326 & 0.0000009 & 0.1308155 & 0.2483888 & 0.0000005 \\
\hline Line10 & $\boldsymbol{F}$ & 267 & 826771.7 & 0.0 & 1 & 75 & 0.0802177 & 0.1207326 & 0.0000009 & 0.1308155 & 0.2483888 & 0.0000005 \\
\hline Line13 & $\boldsymbol{F}$ & 250 & 546259.9 & 0.0 & 1 & 75 & 0.0847886 & 0.1253539 & 0.0000009 & 0.1594664 & 0.4187237 & 0.0000004 \\
\hline Line15 & $F$ & 250 & 546259.9 & 0.0 & 1 & 75 & 0.0847886 & 0.1253539 & 0.0000009 & 0.1594664 & 0.4187237 & 0.0000004 \\
\hline Line16 & $\boldsymbol{F}$ & 250 & 449475.1 & 0.0 & 1 & 75 & 0.0847886 & 0.1253539 & 0.0000009 & 0.1594664 & 0.4187237 & 0.0000004 \\
\hline Line17 & 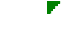 & 250 & 377296.6 & 0.0 & 1 & 75 & 0.0847886 & 0.1253539 & 0.0000009 & 0.1594664 & 0.4187237 & 0.0000004 \\
\hline Line24 & $\boldsymbol{F}$ & 267 & 918635.3 & 0.0 & 1 & 75 & 0.0802177 & 0.1207326 & 0.0000009 & 0.1308155 & 0.2483888 & 0.0000005 \\
\hline Line27 & $\boldsymbol{F}$ & 267 & 55774.3 & 0.0 & 1 & 75 & 0.0802177 & 0.1207326 & 0.0000009 & 0.1308155 & 0.2483888 & 0.0000005 \\
\hline Olorunsogo line 1 & $\boldsymbol{F}$ & 250 & 150918.6 & 0.0 & 1 & 75 & 0.0847886 & 0.1253539 & 0.0000009 & 0.1594664 & 0.4187237 & 0.0000004 \\
\hline Olorunsogo line 2 & $\boldsymbol{F}$ & 250 & 150918.6 & 0.0 & 1 & 75 & 0.0847886 & 0.1253539 & 0.0000009 & 0.1594664 & 0.4187237 & 0.0000004 \\
\hline Sakete line 1 & $\boldsymbol{F}$ & 250 & 32808.4 & 0.0 & 1 & 75 & 0.0847886 & 0.1253539 & 0.0000009 & 0.1594664 & 0.4187237 & 0.0000004 \\
\hline Sakete line 2 & $\boldsymbol{F}$ & 250 & 32808.4 & 0.0 & 1 & 75 & 0.0847886 & 0.1253539 & 0.0000009 & 0.1594664 & 0.4187237 & 0.0000004 \\
\hline Line23 & $\boldsymbol{F}$ & 267 & 918635.3 & 0.0 & 1 & 75 & 0.0802177 & 0.1207326 & 0.0000009 & 0.1308155 & 0.2483888 & 0.0000005 \\
\hline
\end{tabular}

